THE IMPACT OF POSITIVE MOODS ON SITUATIONAL PREFERENCES

\author{
AND FEELING SOCIABLE \\ A thesis submitted to \\ The Faculty of Graduate Studies and Research \\ in partial fulfillment of the requirements for the degree \\ Master of Arts
}

by

Deanna C. Whelan

Department of Psychology

Carleton University

August, 2008

(C) Deanna C. Whelan 


$\begin{array}{ll}\begin{array}{l}\text { Library and } \\ \text { Archives Canada }\end{array} & \begin{array}{l}\text { Bibliothèque et } \\ \text { Archives Canada }\end{array} \\ \begin{array}{l}\text { Published Heritage } \\ \text { Branch }\end{array} & \begin{array}{l}\text { Direction du } \\ \text { Patrimoine de l'édition }\end{array} \\ \begin{array}{l}\text { 395 Wellington Street } \\ \text { Ottawa ON K1A ON4 } \\ \text { Canada }\end{array} & \begin{array}{l}\text { 395, rue Wellington } \\ \text { Ottawa ON K1A 0N4 } \\ \text { Canada }\end{array}\end{array}$

Your file Votre référence ISBN: 978-0-494-44024-7

Our file Notre référence

ISBN: 978-0-494-44024-7

NOTICE:

The author has granted a nonexclusive license allowing Library and Archives Canada to reproduce, publish, archive, preserve, conserve, communicate to the public by telecommunication or on the Internet, loan, distribute and sell theses worldwide, for commercial or noncommercial purposes, in microform, paper, electronic and/or any other formats.

The author retains copyright ownership and moral rights in this thesis. Neither the thesis nor substantial extracts from it may be printed or otherwise reproduced without the author's permission.
AVIS:

L'auteur a accordé une licence non exclusive permettant à la Bibliothèque et Archives Canada de reproduire, publier, archiver, sauvegarder, conserver, transmettre au public par télécommunication ou par l'Internet, prêter, distribuer et vendre des thèses partout dans le monde, à des fins commerciales ou autres, sur support microforme, papier, électronique et/ou autres formats.

L'auteur conserve la propriété du droit d'auteur et des droits moraux qui protège cette thèse. $\mathrm{Ni}$ la thèse ni des extraits substantiels de celle-ci ne doivent être imprimés ou autrement reproduits sans son autorisation.
In compliance with the Canadian

Privacy Act some supporting forms may have been removed from this thesis.

While these forms may be included in the document page count, their removal does not represent any loss of content from the thesis.
Conformément à la loi canadienne sur la protection de la vie privée, quelques formulaires secondaires ont été enlevés de cette thèse.

Bien que ces formulaires aient inclus dans la pagination, il n'y aura aucun contenu manquant.

\section{Canada}




\begin{abstract}
The broaden-and-build theory suggests that positive emotions allow people to feel and become more connected to others. This research explored whether or not positive moods made people more sociable (i.e., want to affiliate with others more). Three studies found, through experimental manipulation of moods, that people in positive moods reported feeling more social. Furthermore, people in positive moods showed preference for social over non-social situation regardless of the situations being pleasant or unpleasant. Interestingly, no behavioural differences were found during a brief social interaction. Therefore, this research largely supports the broaden-and-build theory in that positive moods may also foster affiliating with others to create the socializing experiences. These findings align with prior research while addressing two major confounds of past studies.
\end{abstract}




\section{Acknowledgements}

Thank you to my advisor John Zelenski who, once again, supported me in my research and allowed me to select a topic with personal importance. I would also like to thank him for all of his "jerky" questions that made me critically think through decisions, analyses, and how I described them.

Thank you to Kim Cullen who spent much time and effort helping me collect and code data. It was not only critical to the successful completion of this thesis but was also a source of our many enjoyable conversations.

Thank you to my family and close friends who let me talk through my ideas, read through drafts, and were my brains when mine failed. I am grateful and honoured to be surrounded by so many wonderful people that I can count on and whose support and guidance I know I can trust. There are simply not enough words to express my gratitude.

Thank you to all my friends for the emotional support that you provided me. It kept my spirits up and made me keep trying even when the task seemed impossible. A special thank you to my friends at Foundation Restaurant. The support, encouragement, laughter, and entertaining evenings that we shared were more important to the successful completion of this project than you may realize.

Two down, one to go! 


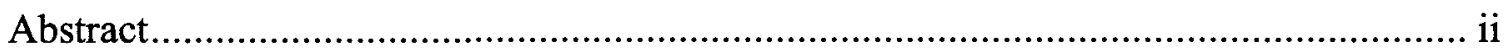

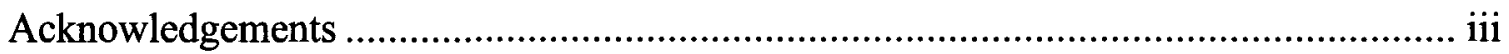

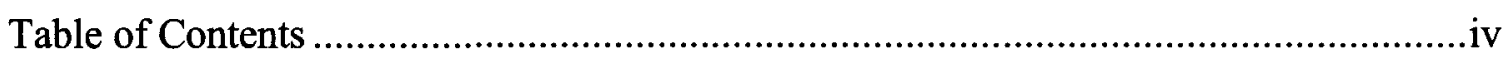

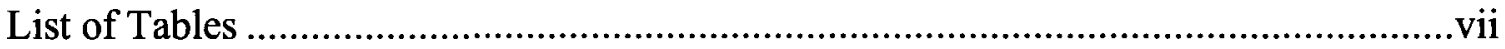

List of Figures .......................................................................................... viii

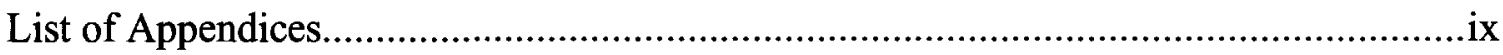

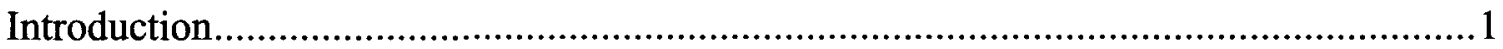

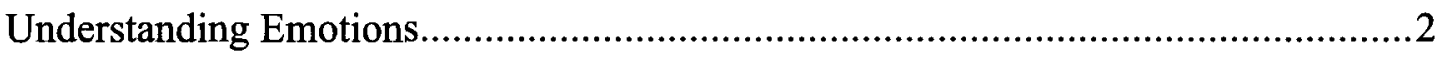

Understanding Positive Emotions - the Broaden-and-Build Theory ....................5

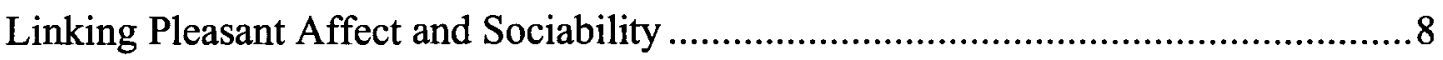

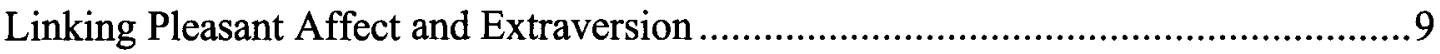

Linking Pleasant Affect as a Temporary State............................................... 12

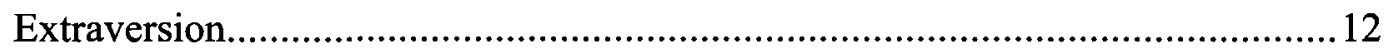

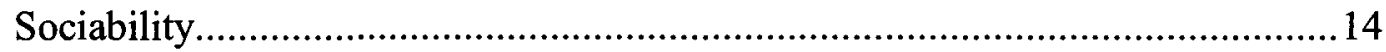

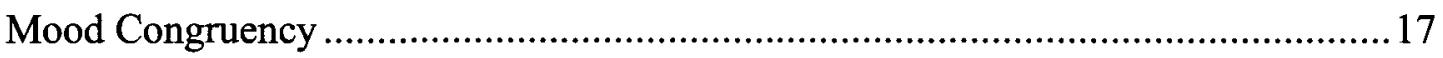

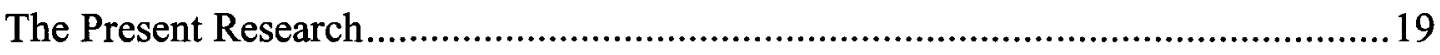

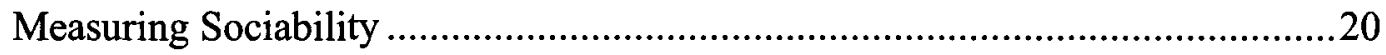

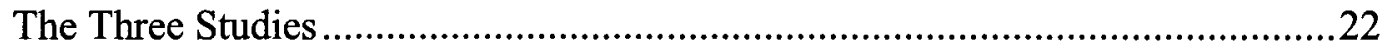

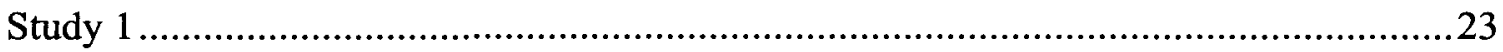

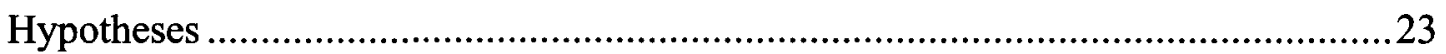

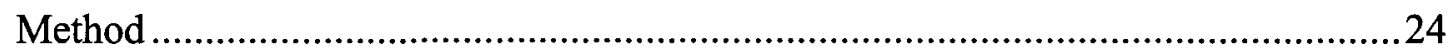

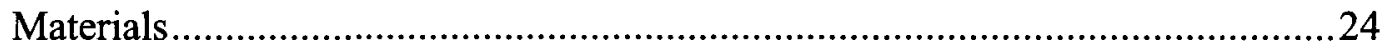


Procedure.

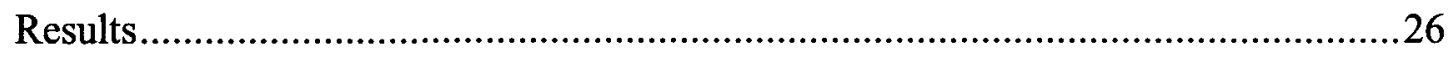

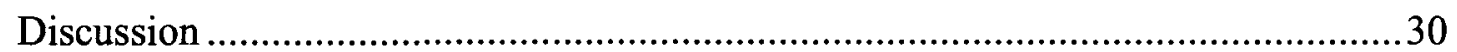

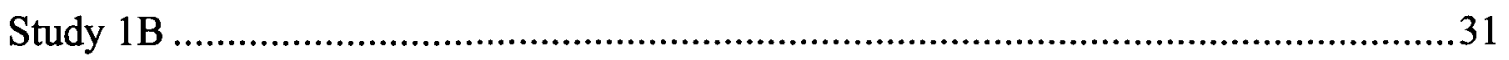

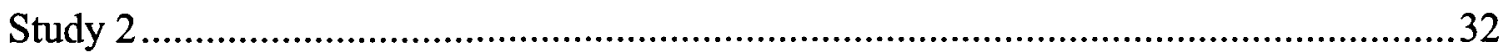

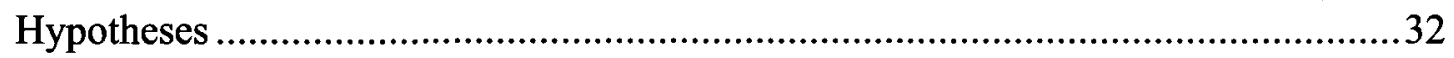

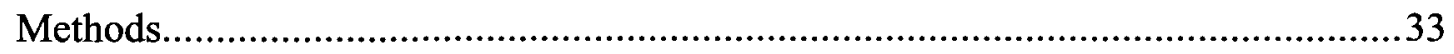

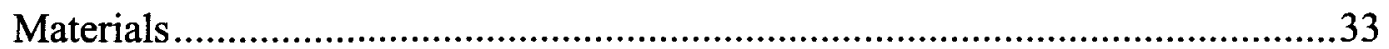

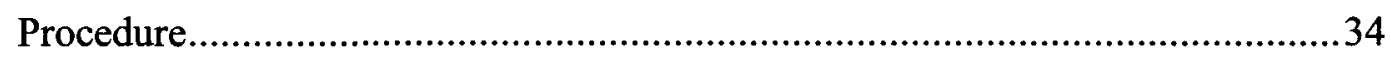

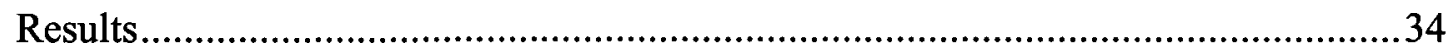

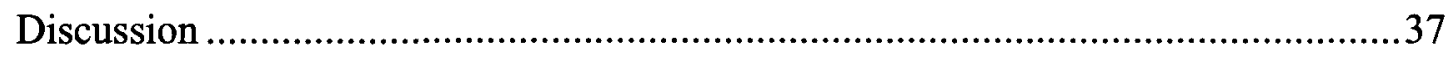

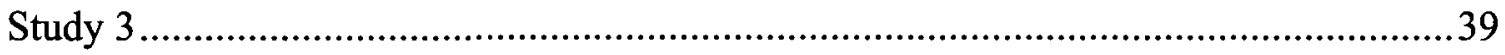

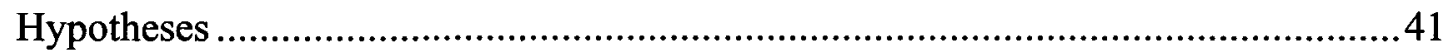

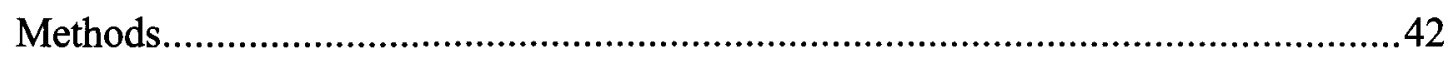

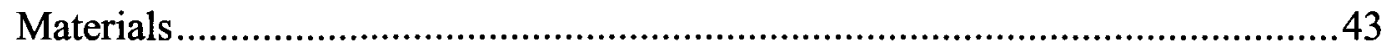

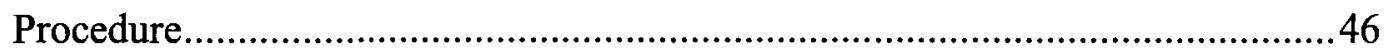

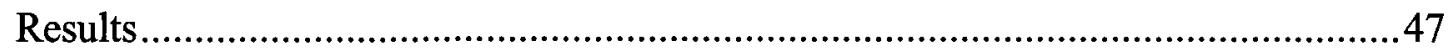

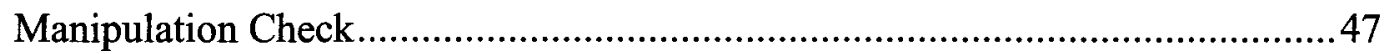

Feeling Extraverted and Feeling Sociable........................................................48

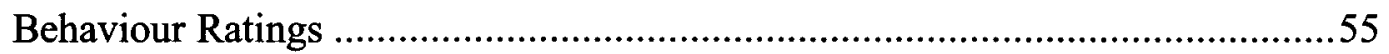

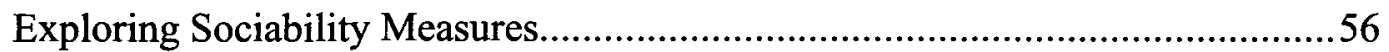

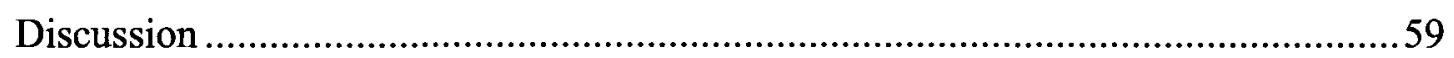

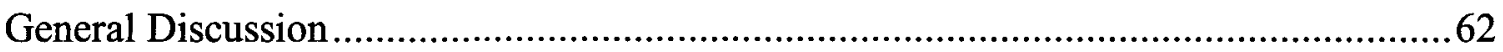


Strengths and Limitations

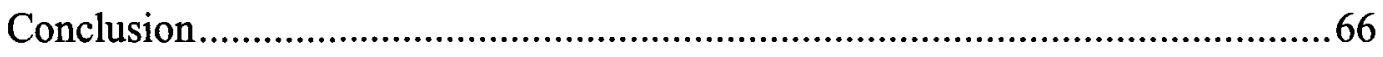

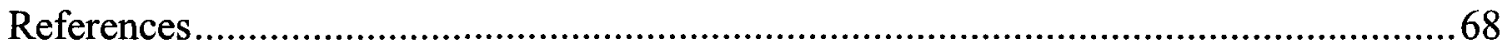

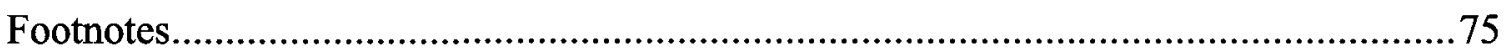




\section{List of Tables}

Table 1 Comparison of Affective Terms by Mood Condition for Study 1

Table 2 Regression Analyses for Trait Extraversion, Condition and their Interaction on

Feeling Extraverted for Study 1.

Table 3 Comparison of Affective Terms by Mood Condition for Study 2. .35

Table 4 Regression Analyses for Trait Extraversion, Condition and their Interaction on

Feeling Extraverted for Study 2.

Table 5 Means and Standard Deviations for Ratings of Pleasantness and Socialness for

Situational Categories (Study 3).

Table 6 Comparison of Affective Terms by Mood Condition for Study 3.

Table 7 Regression Analyses for Trait Extraversion, Condition, and their Interaction on

Feeling Extraverted for Study 3.

Table 8 Regression Analyses for Trait Extraversion, Condition, and their Interaction on

Feeling Sociable for Study 3.

Table 9 Repeated Measures ANOVA results for Socialness $x$ Pleasantness $x$ Condition. 54

Table 10 Comparison of Observer Ratings and Speaking Times by Mood Condition

(Study 3)

Table 11 Correlations Between Sociability Measures. 


\section{List of Figures}

Figure 1. The Affect Circumplex (Larsen \& Diener, 1992).....................................4

Figure 2. Feeling extraverted as a function of trait extraversion and mood condition. ....29

Figure 3. Rating of desire for situation for mood condition by socialness interaction

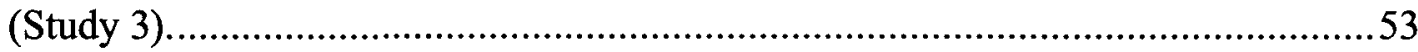

Figure 4. Rating of desire for situation for mood condition by socialness interaction for pleasant situations (Study 3).

Figure 5. Rating of desire for situation for mood condition by socialness interaction for unpleasant situations (Study 3). 


\section{List of Appendices}

Appendix A - Trait Extraversion Assessment .............................................................76

Appendix B - Affect and Feeling Extraverted Assessment ………….............................77

Appendix C - Situations Questionnaire Study 1 .......................................................78

Appendix D - Film Questionnaire ………………....................................................79

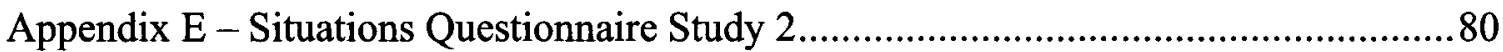

Appendix F - Condition by Pleasantness Analysis (Study 2) …...................................81

Appendix G - Affect, Feeling Extraverted and Sociability Assessment...........................82

Appendix H -Situations for On-line Pre-Screening......................................................... 83

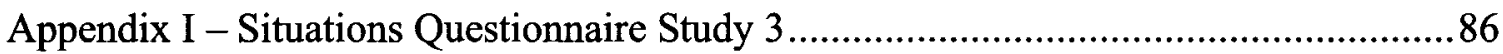




\title{
THE IMPACT OF POSITIVE MOODS ON SITUATIONAL PREFERENCES
}

\section{AND FEELING SOCIABLE}

\author{
Deanna C. Whelan
}

It is well established that socializing and spending time in social situations are associated with positive moods. Social interactions are generally pleasant such that being placed into a social interaction results in reports of greater pleasant emotions (Vittengl \& Holt, 2000). The broaden-and-build theory links positive emotions and social interactions such that positive emotions allow people to feel and become more connected to others (Fredrickson, 1998, 2001). Consequently, positive emotions foster social relationships. These social relationships can then be drawn on during times of stress and thus are seen as providing long-term benefits. In this way, the broaden-and-build theory proposes that positive emotions are evolutionarily adaptive. The research presented here tests one aspect of the broaden-and-build theory by exploring whether or not positive moods make people more sociable (i.e., want to affiliate with others more).

Research supports the notion that positive moods lead to sociability (Cunningham 1988a, 1988b). Unfortunately, there are alternative explanations for the results. One of the challenging aspects of studying socializing is that social situations are more enjoyable relative to non-social situations; therefore it is difficult to determine if preference for a social situation is due to it being social or due to it being pleasant.

The goal of the present research is to examine the short-term changes in sociability following mood manipulations. Three separate studies explore whether or not positive moods make you feel more social while addressing confounds and limitations of past research. Furthermore, the personality construct of extraversion is explored in 
relation to mood and sociability as extraverts tend to be both more positive and more social.

\section{Understanding Emotions}

A number of words are used to describe emotion-related phenomena (e.g., feeling, emotion, affect, mood, etc.), and it is useful to clearly understand nuances in their meaning. Emotions arise from personally meaningful circumstances and are conceptualized as belonging to distinct categories such as fear or interest. They are specific and short-lived. Furthermore, emotions are frequently seen as a reaction to an event. This contrasts with moods which are more enduring and can be the result of unknown causes (Reeves, 2005). For instance, the act of stubbing your toe might immediately elicit the emotion of anger. This emotion will last for a very brief time, perhaps only a few seconds. The possible longer-term negative emotional mindset, resulting from stubbing your toe earlier in the day (and many other occurrences), is termed mood. Furthermore, the term affect contrasts emotions in that it does not require personal meaning and is therefore more "free floating" or general compared to emotions (Fredrickson, 2001). Therefore, unlike emotions, which are specific, mood and affect are more general and have longer durations.

Affective experiences are frequently conceptualized as being composed of two separate components, arousal and pleasantness (Larsen \& Diener, 1992). That is, emotional experience can be high or low in arousal and concurrently pleasant or unpleasant. The affect circumplex is a two-dimensional structure that graphically represents affective experiences; arousal forms the vertical axis while pleasantness forms the horizontal axis (Russell, 1980). The term dimension is utilized when referring to 
bipolar terms at 180 degrees. The arousal dimension is anchored by terms such as active and inactive whereas the pleasantness dimension is anchored by terms such as sad and happy. The spacing of affective terms on the circumplex is such that terms that correlate with one another in experience are spaced nearby (happy and cheerful), those inversely correlated are on the opposite side of the circle (happy and sad), whereas those with near zero correlations are at ninety degrees (happy and quiet). See Figure 1. The circumplex can be further divided by two orthogonal dimensions named positive affect and negative affect. Positive affect and negative affect dimensions have high arousal and low arousal components. This contrasts to the term positive affect which is restricted to affective terms that are both high in arousal and pleasant (i.e., one end of the positive affect dimension). Equally, negative affect is restricted to affective terms that are both high in arousal and unpleasant. Therefore, for a low score on positive affect/negative affect it is not possible to know if a subject is feeling bored/relaxed or merely not feeling excited/distressed (Larsen \& Diener, 1992). That is, a low score of feeling excited does not equate to a high score on feeling bored. Therefore, positive affect and negative affect are more specific when contrasted with the more general emotional experience termed affect. Pleasant affect and Unpleasant affect will be used when discussing general affective experience that are valenced whereas the terms positive affect and negative affect will be used when referencing the high arousal components of the affect circumplex. 


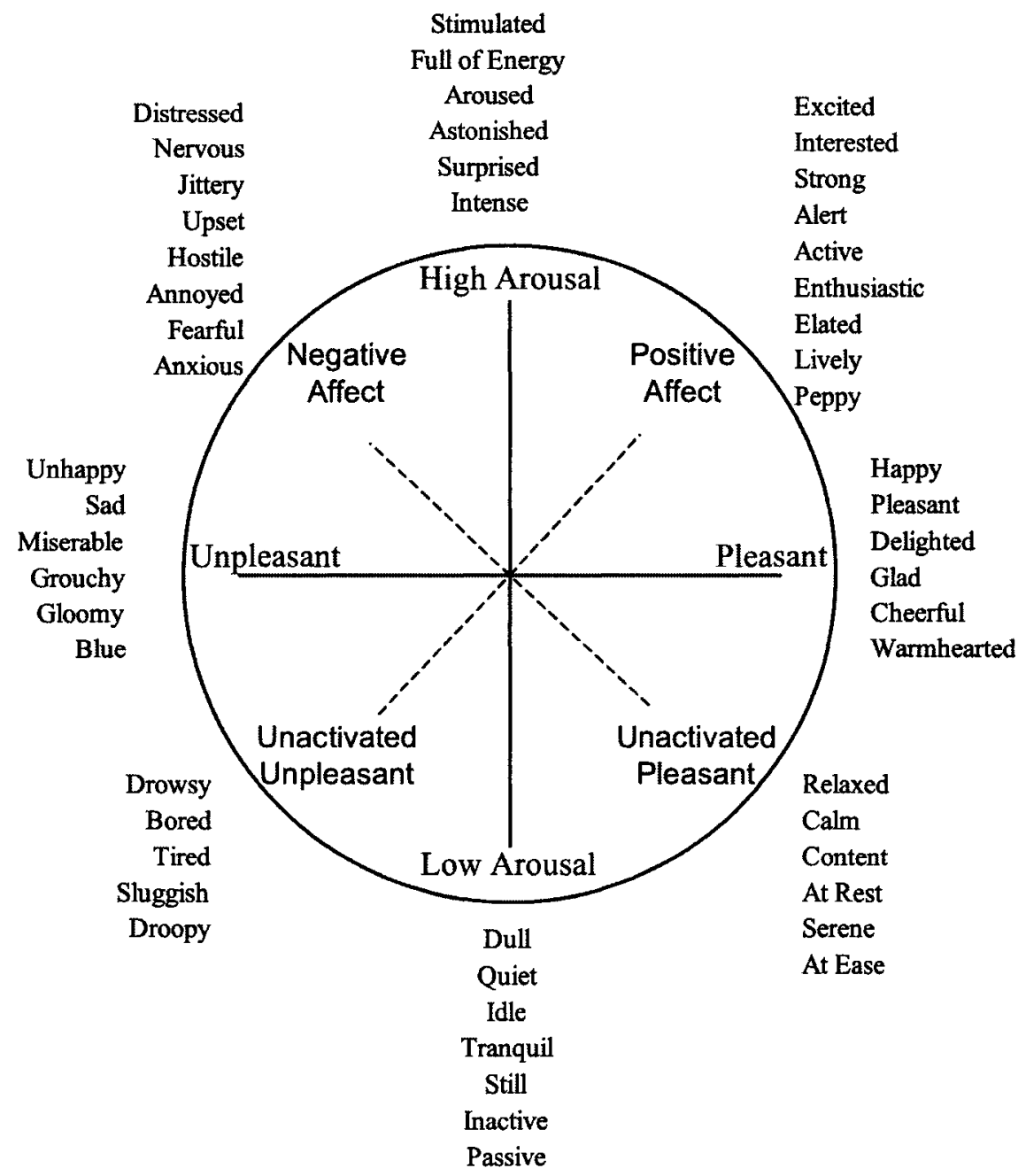

Figure 1. The Affect Circumplex (Larsen \& Diener, 1992)

Regardless of classification, emotions impact the way we feel, think, and behave (Reeve, 2005). The purpose of emotions, as viewed by discrete or basic emotion theorists, is that they direct our attention and channel behaviour. Specifically, the discrete emotion stance links emotions with specific action tendencies that are considered evolutionarily adaptive (Reeve, 2005). That is, a particular emotion evokes specific behavioural options by narrowing a person's thought-action repertoire. Fear evokes the urge to escape, anger the urge to attack, and guilt the urge to make amends. Emotions are seen as evolutionarily adaptive due to the behavioural element. For example, fear 
instigates the desire to flee which can be evolutionarily adaptive in that by running away from dangerous situations, you may live to survive another day. Therefore, negative emotions have a direct and immediate benefit in the form of adaptive behaviour.

Discrete emotion theory also proposes that physiological changes occur along with the narrowing of thought and action. The physiological changes prepare for the possibility of action; in the case of fear, the body is mobilized for running (Levenson, 1994). Support for discrete emotion theory is compelling for negative emotions (see Derryberry \& Tucker, 1994). Unfortunately, discrete emotions theory falls short with regard to positive emotions.

Positive emotions differ from negative emotions in that they are fewer in number and are less distinct (Fredrickson, 1998). Negative emotions such as fear and anger are distinctive whereas joy and love are not as easily differentiated. This lack of differentiation extends to physiological changes and facial displays of positive emotions. Furthermore, both English language and taxonomies of discrete emotions have one positive emotion for multiple negative emotions (see Fredrickson, 1998 for a further review of differences between positive and negative emotions). The broaden-and-build theory of positive emotions was advanced to explain the differences between positive and negative emotions and suggest functions for positive emotions (Fredrickson, 1998, 2001). Understanding Positive Emotions-the Broaden-and-Build Theory

The broaden-and-build theory posits that positive emotions serve to build physical, intellectual, and social resources (Fredrickson, 1998, 2001). It also posits that positive emotions serve an evolutionary, adaptive function, by broadening the scope of attention and cognition. That is, changes in thoughts and behaviour patterns that follow 
from positive emotions allow individuals "to pursue novel, creative, and often unscripted paths of thought and action" (Fredrickson, 1998, p. 304). For example, joy creates the urge to play and be playful, contentment encourages contemplation and reflection, and interest inspires exploration to gain knowledge.

Discrete emotion theory predicts a narrowing of thought and action (a funnelling effect on one's focus) whereas the broaden-and-build theory predicts a broadening (a horseshoe shape or an inverted V). Furthermore, the evolutionary adaptive functions of negative emotions are direct and short term, whereas positive emotions, as suggested by Fredrickson (2001), may be more indirect and long term. For instance, positive emotions are linked to approach-oriented behaviours (Carver, Sutton, \& Scheier, 2000). By broadening exploratory behaviour, there can be greater opportunities for developing knowledge about the environment. This greater knowledge is then a personal resource. Therefore, a positive emotion may be transient while the benefit of experiencing the positive emotions may be more permanent (Fredrickson, 2001).

The positive emotions of the broaden-and-build theory are seen as a collection of positively-valenced emotions (Fredrickson, 2001). The characteristic blending of positive emotions creates a more vague or general emotional experience. Thus, the positive emotions of the broaden-and-build theory can be seen as pleasant affect (recall that emotions are differentiated from affect by their specificity). Furthermore, the consequences of positive emotions proposed by the broaden-and-build theory are not limited to the short-term experience of the emotion but more long-term. "Positive emotions also produce flourishing. Moreover, they do so not simply within the present, pleasant moment but over the long term as well" (p. 218). The lasting experience or 
effects of emotional episodes are normally termed mood. Therefore, although Fredrickson refers to positive emotions, the processes she describes fit very well with the more long-term, generalized idea of moods. My research tests an aspect of the broadenand-build theory by manipulating moods.

Positive emotions (moods) are theorized to build social resources in that the positive emotions that occur during play and cooperation form the basis for social connections. The social connections in turn provide the opportunity for enduring alliances, friendships and family bonds that can be drawn on during times of adversity. The mechanism by which positive emotions cultivate social closeness and build lasting relationships may facilitate more inclusive social categories (Waugh \& Fredrickson, 2006). Cognitively, when people are in good moods they identify more with others (higher self-other overlap). This allows for a more complex understanding of others, which in turn, allows for a better appreciation and thus increased closeness (Waugh \& Fredrickson, 2006). Fredrickson (1998) discusses the indirect support for positive emotions building social resources. For example, infant-caregiver relationships (where infants smile prior to the ability to recognize facial characteristics), social play, and cooperation and turn taking all link social resources and positive emotions. Diener and Seligman (2002) provide additional support; very happy people tend to have "stronger" social relationships. Waugh and Fredrickson (2006) found direct support in that positive emotions predicted self-other overlap among roommates of first year university students living in residence during their first weeks on campus. Therefore, it appears that positive emotions foster identifying with others.

Positive emotional states fostering the desire to affiliate with others may be a 
complementary process for building social resources. That is, another way that positive emotions facilitate social resources is by encouraging sociability and thereby providing opportunities to interact and identify with others. Therefore, positive emotions may encourage social interactions. Importantly, Cunningham (1988b) provides support for the idea that positive moods foster the desire to affiliate with others.

\section{Linking Pleasant Affect and Sociability}

Although not all social interactions are positive, social situations are generally pleasant (Lucas \& Diener, 2001). Similarly, social interactions are associated with higher levels of pleasant affect (Clark \& Watson, 1988; McIntyre, Watson, Clark \& Cross, 1991; Vittengl \& Holt, 2000; Watson, 1988; Watson, Clark, \& McIntyre, 1990 as cited by Watson \& Clark, 1997; Watson, Clark, McIntyre, \& Hamaker, 1992). Furthermore, the amount of time spent in social situations is also correlated with trait positive affect (a stable disposition towards experiencing more positive affect, Pavot, Diener, \& Fujita, 1990). Moreover, very happy people appear to have stronger social relationships and are more social compared to less happy individuals (Diener \& Seligman, 2002). The link between positive affect and social activity has been assessed in a variety of ways including; time with friends (Watson, 1988), occurrence of specific social events (e.g., going to a concert/movie, Watson et al. 1992), frequency (rated on Likert scale) for types of social activity (Watson, et al. 1990 as discussed by Watson \& Clark, 1997), and count of occurrence of spontaneous social events (Clark \& Watson, 1988).

A typical study examines, through time sampling or diary methods, the correlations between social activity and positive affect (measured either trait or state or in combination). For example, Watson et al. (1990) had participants rate adjectives (to 
assess their moods) and social activities. This information was collected weekly for a period of 13 weeks. Results linked socializing, frequency of participating in social activities, with positive affect. A less direct source of support for the idea that positive moods are associated with sociability comes from research on the personality trait of extraversion: in particular, research exploring extraversion and pleasant affect. For example, Watson et al. also found that socializing was also linked to the personality trait of extraversion. However, prior to discussing the research linking positive moods and sociability, extraversion will be defined.

\section{Linking Pleasant Affect and Extraversion}

Extraversion, and its opposite introversion, are the anchors of a single dimension and do not necessarily refer to a typology. Most people fall somewhere along the continuum and are thus difficult to label as either extraverts or introverts (although it is important to note that extreme cases can be found). The personality trait of extraversion is a higher-order trait that encompasses many facets. In general, the key characteristics of extraverts are that they are social and dominant, they are also frequently conceptualized as active or full of energy. “... Extraverts are gregarious, friendly, dominant, and socially facile. They enjoy being with other people and are confident and comfortable with interacting with them" (Watson \& Clark, 1997, p. 771).

Extraversion has been defined in a variety of ways. Eysenck uses the adjectives sociable, lively, active, assertive, sensation seeking, carefree, dominant, surgent and venturesome to define the trait (Eysenck \& Eysenck, 1985). Costa and McCrae define extraversion as warm, gregarious, assertive, active, excitement seeking, and positive affect (Watson \& Clark, 1997). There are similarities between these two definitions; both 
use the terms active and assertive as well as a component of seeking out stimulation (sensation seeking versus excitement seeking). There are also differences between the two definitions, most notably Costa and McCrae's inclusion of positive affect. Comparable similarities and differences exist when comparing other definitions of extraversion (see Watson \& Clark, 1997 for a review of theoretical stances of extraversion and their facets). ${ }^{1}$

Despite the agreement on key characteristics of extraversion, there is much debate on the causal contributions of trait extraversion. Specifically, debate regarding differing perspectives concerning the core construct of extraversion can be found. Positive affect (Tellegen, 1985), social activity (Hills \& Argyle, 2001), reward sensitivity (Lucas, Diener, Grob, Suh, \& Shao, 2000), and approach motivation (Carver et al. 2000) have each been put forth as the fundamental feature of extraversion. The controversy surrounding the core component of extraversion focuses on determining if there is a single key feature and attempting to define and label it. Of importance here is the broader concept of extraversion and its covariation with both positive affective experiences and social ease. That is, irrespective of how extraversion seems to be defined, its link to pleasant affect and socially facile behaviour is found.

Research has shown that on average extraverts report more pleasant affect compared to introverts (Diener \& Seligman, 2002; Diener, Suh, Lucas, \& Smith, 1999; Hills \& Argyle, 2001; Lucas \& Fujita, 2000). In fact, this link is one of the most consistently replicated and stable findings in the subjective well-being literature (Diener et al. 1999). Consequently, extraversion's link to pleasant affect is not contested. Similarly, extraversion's link to socially facile behaviour is not contested as one of the agreed upon 
characteristics of extraversion is that they are more social compared to introverts. The explanation for this pattern of covariation, however, is still a matter of debate.

In an attempt to understand the extraversion-pleasant affect link, Lucas et al. (2000) conducted four studies to explore the key facets of extraversion. They explored whether reward sensitivity (ability to detect or respond more vigorously to positive stimuli) or sociability formed the core of trait extraversion. That is, is reward sensitivity the critical facet to the larger super-ordinate trait of extraversion? They used structural equation modelling (SEM) to examine the correlations from college students in the United States followed by a test of the model's generalizability to an international sample. They found, consistently across 39 cultures, that sensitivity to reward and extraversion were strongly related. Additionally, they found extraversion and pleasant affect to be related but pleasant affect to be unrelated to social interaction. They concluded that sensitivity to reward forms the core of extraversion. Although sociability was still considered an important part of extraversion, they also concluded that “extraverts' sociability may be a by-product of reward sensitivity" (Lucas et al. 2000, p. 452). Thus, Lucas et al. deduce that extraverts may select social situations due to the rewarding qualities of the situations and not their social characteristics. Consistent with this concept is that extraverts react more strongly to positive stimuli (Larsen, \& Ketelaar, 1991; Zelenski \& Larsen, 1999).

Lucas and Diener (2001) provide additional support for this idea by examining extraversion and enjoyment of various situations. They had participants complete personality measures and rate how happy they would feel in different situations (social and non-social) that varied on level of pleasantness. They found that extraversion was 
correlated with enjoying pleasant situations (for both social and non-social) but not unpleasant situations (either social or non-social). Importantly, extraverts' greater enjoyment of pleasant situations did not differ substantially between social and nonsocial situations. That is, extraverts were not particularly responsive to social cues, but rather pleasant (reward) cues more generally.

Despite Lucas et al.'s (2000) conclusion that the core of extraversion is reward sensitivity, there is an alternative process that aligns with the broaden-and-build theory. Specifically, reward sensitivity may cause increases in pleasant affect that in turn causes extraverts to seek out social situations. That is, extraverts' sensitivity to positive stimuli, in all environments, causes increases in pleasant affect. The higher levels of pleasant affect then cause extraverts to select social situations, which are more pleasant than nonsocial (Lucas \& Diener, 2001).

\section{Linking Pleasant Affect as a Temporary State}

Pleasant affect and its link to both extraversion and socialness is persuasive although the research discussed thus far has examined trait extraversion and/or positive affect as a stable disposition. That is, traits are durable dispositions or response tendencies whereas states are comparatively short-lived. The objective of the research presented in the paper is to determine whether or not positive moods cause increases in sociability while statistically controlling for trait extraversion. The mood inductions used are not expected to alter trait positive affect but state positive affect and state pleasant affect, in that they would be temporary. Likewise, the expected changes in sociability would also be more state oriented or short-lived.

Extraversion 
Extraverts demonstrate extraverted characteristics more frequently than introverts, but this does not imply that people are always consistent in their behaviour. In fact, when examining moment-to-moment behaviour there are large variations (Fleeson, Malanoz, \& Achille, 2002). People behave differently due to situational demands or personal objectives. However, when behaviour is aggregated over time it is very stable (Epstein, 1983), and this is the keystone of personality traits.

Taking a different approach to exploring the link between extraversion and positive affect, Fleeson et al. (2002) examined if within-person variations in extraverted behaviour correlated with positive affect. Fleeson's density distribution of states model of personality (2001) predicts that moment-to-moment variations in behaviour (e.g., behaving extraverted) should correspond to the same affective states (e.g., positive affect) that are found when behaviour and affect are averaged over time. That is, behaving extraverted should be associated with positive affect, regardless of disposition (trait introvert or trait extravert).

In exploring whether or not extraverted behaviour was associated with positive affect, Fleeson et al. (2002) conducted two studies using self-report experience-sampling methodology and one study where behaviour was experimentally manipulated. The experience-sampling studies examined self-reported behaviour and affect over two different time periods ( 3 hour time periods compared to average weekly ratings). Both studies found that self-reported extraverted behaviour and positive affect co-occurred in both dispositional introverts and dispositional extraverts.

To experimentally manipulate behaviour, Fleeson et al. (2002) assigned participants to one of two conditions; acting extraverted and acting introverted. Those in 
the acting extraverted condition were instructed to act bold, talkative, energetic, active, assertive, and adventurous whereas those in the acting introverted condition were instructed to act reserved, quiet, lethargic, passive, compliant, and unadventurous during group discussions. Participants in the acting extraverted condition reported higher levels of positive affect compared to those in the acting introverted condition. Fleeson et al. concluded that "individuals can increase their positive affect by increasing their extraversion" (2002, p. 1418).

The experimental study by Fleeson et al. (2002) suggests that, at the state level, extraverted behaviour causes pleasant affect (specifically positive affect). This contrasts Lucas et al.'s (2000) conclusion that extraverts' sociability is a by-product of pleasant affect. Furthermore, Fleeson et al.'s findings do not rule out the reverse causal direction-the possibility of higher levels of positive affective states causing increases in feeling and behaving socially/extraverted. In fact, this process has previously been hypothesized (Diener, Sandvik, Pavot, \& Fujita, 1992; Emmons \& Diener, 1986; Fredrickson, 1998, 2001; Lucas et al. 2000; McIntyre et al. 1991; Pavot et al. 1990). Unfortunately, there are few empirical studies exploring pleasant affect and its potential causal influence on sociability.

\section{Sociability}

In exploring the association of pleasant affect and social contexts, experimental studies have found that people report higher levels of pleasant affect after being placed in social situations (McIntyre et al. 1991; Vittengl \& Holt, 2000; Whelan, 2006, 2007). Therefore, in alignment with Fleeson et al. (2002), socializing appears to cause pleasant affect. In exploring the reverse direction, in alignment with the primary goal of this 
dissertation—positive moods causing sociability, Cunningham (1988a) examined the extent of self-disclosure (intimate or superficial) among males in positive and negative mood conditions. Specifically, following mood manipulations (two different methods for positive and negative, i.e., four conditions), the researcher informed participants that due to technical problems they would be required to wait 15 minutes. The researcher brought each male participant to a waiting area. A second researcher then brought a female confederate into the room. If the conversation between the confederate and participant lagged for more than 1 minute, the confederate asked a question. Two researchers listened to the conversation between the participant and confederate and coded each approximate spoken sentence for level of self-disclosure. Results indicated more selfdisclosure in the positive mood conditions compared to the negative mood conditions. Additionally, people in the positive mood conditions spoke more (i.e., more sentences) compared to people in the negative mood conditions. Cunningham concluded "that positive mood increases sociability" (1998a, p. 283).

Although his findings are suggestive, Cunningham's (1988a) conclusion about positive moods, per se, is problematic. Consider that his two negative inductions included a film "tour of a concentration camp and photographs of Nazi atrocities" (Cunningham, 1988a, p. 287) and false failure feedback. This compares to seemingly more mild positive inductions of "upbeat music and stimulating graphics" (p. 287) and false positive feedback (likely weaker than negative feedback because most people already believe they are better than average [Greenwald, 1980; Taylor \& Brown, 1988]). Therefore, the difference in mood conditions may be due to participants in the negative mood conditions feeling badly, more than those in the positive mood conditions feeling happy. 
Furthermore, because Cunningham (1988a) did not have a neutral condition, his conclusion that positive moods increase sociability can be questioned. An equally plausible explanation is that negative moods decrease sociability. This possibility is most readily examined through the addition of a neutral or control condition.

In a second study, Cunningham (1988b) examined situational preferences under three different mood conditions: elation, neutral, and depression. Moods were induced with the Velten Mood Induction Procedure (VMIP, Velten, 1968) in which participants read statements such as "Things will be better and better today," (elated) "Utah is a beehive state" (neutral) and "Everything seems futile and empty" (depressed) for the respective mood conditions. Participants then rated how much they wanted to engage in 137 activities from the Pleasant Events Schedule (PES, MacPhillamy \& Lewinsohn, 1982). Cunningham (1988b) found that preferences for social activities differed by mood condition with those in the elation mood condition desiring social activities more than those in either the neutral or depression conditions. Additionally, no difference between mood conditions was found for non-social situations. Cunningham's findings support the notion that positive moods make people desire more social situations.

Cunningham's (1988b) findings are again suggestive, but the methods again raise some questions. The VMIP procedure has been criticized for demand effects to the extent that Buchwald, Strack and Coyne (1981) concluded that the mood induction procedure should not be used. Following a meta-analytic study on the effects of the VMIP, Larsen and Sinnett (1991) conclude that the VMIP is susceptible to demand but there are still mood effects even when demands have been minimized. Unfortunately, Cunningham's procedure likely included additional demand effects. That is, it included telling 
participants the purpose of the experiment was to "determine how people in different states of mind responded to different types of social, recreational, and work activities" (1988b, p. 316). Following the mood induction, participants were asked to indicate honestly whether they felt that the VMIP had altered their moods. These procedural aspects appear to have additional demand effects beyond those normally associated with the VMIP. That is, participants were specifically asked if the VMIP had altered their mood and were informed that the experiment was trying to determine if people in different moods would differ on their ratings of situations. It is possible that participants guessed at the hypotheses Cunningham was testing and responded accordingly. Regrettably, it is not possible to determine which components of Cunningham's (1988b) findings were due to moods and which were due to demand effects.

Cunningham (1988b) concludes that people in the positive mood condition show preference for social activities compared to people in both neutral and negative moods. There is another alternative explanation for Cunningham's (1988b) findings beyond demand. Specifically, those in the positive mood condition show preference for the most pleasant situations, which happen to be social. This match between an individual's mood and their preferences is termed mood congruency, and the idea provides a challenge in testing the link between mood and sociability. (Recall that most social situations are positive, c.f., Lucas \& Diener, 2001).

\section{Mood Congruency}

Mood congruency is the tendency to dwell on or preferentially process information that aligns with current feelings (Bower, 1991; Mayer, Gaschke, Braverman, \& Evans, 1992). The mood-congruency theory stems from the proposed network model 
of affect, which puts forth that distinct emotions, such as joy and fear, have specific nodes or units in memory. These nodes are linked to other information stored in memory such as places, events, or facial expressions related to the emotion. Some associations are innate while others are learned (Bower, 1981). By activating an emotion node, the linkages associated with that emotion also become activated and the associated information becomes more readily accessible. The mood-congruency hypothesis postulates that if mood and material are consistent the material will be learned and remembered better than if mood and materials are inconsistent (Rusting, 1998). That is, learning positive material such as a list of positive words will be easier and remembered better if the learning occurred in a positive mood state compared to a negative mood state. The greater accessibility of emotion nodes can then influence a variety of cognitive process that interact with memory. For example, people in positive moods judge positive events as more probable compared to judgements made by those in negative moods (Johnson \& Tversky, 1983; Wright \& Bower, 1992).

Also consistent with Bower's theory, people in positive mood states tend to rate positive stimuli more favourably, compared to people in negative moods, and people in negative mood states tend to rate negative stimuli more favourably compared to people in positive moods (Kelley, 1982). This has important implications for interpreting Cunningham's (1988b) results. Recall that Cunningham (1988b) found that people in positive moods rated social situations more desirable than people in negative and neutral moods. As all the situations in the Pleasant Events Schedule are relatively pleasant, there would be a general trend of rating all the situations more favourable under the elation condition relative to the neutral and depression conditions used by Cunningham (1988b). 
Cunningham's (1988b) results show this general response trend. Therefore, Cunningham's (1988b) findings may be due to the positivity of the situations and not the socialness per se.

Considering mood congruence effects also reveal a more general challenge to studying the link between positive moods and sociability. Research has shown that social situations are generally more pleasant than non-social situations (Lucas \& Diener, 2001). That is, although some social situations are unpleasant (e.g., fighting with a friend) these are a minority of all social situations. Mood congruency would predict that people in positive moods would rate the most pleasant situations as the most desired. Based on Lucas and Diener's (2001) findings, the most pleasant situations would be social. My research attempted to examine the preference for social situations while considering their pleasantness to avoid this potential confound.

\section{The Present Research}

In alignment with the broaden-and-build theory, the goal of the present research was to examine potential short-term changes in sociability due to mood manipulations as an additional method for positive moods fostering social resources. Specifically, three separate studies explored whether or not positive moods increased feelings of sociability. Furthermore, as positive moods and sociability are both associated with trait extraversion, all three studies statistically controlled for trait extraversion. As extraverts react more strongly to positive stimuli (Larsen, \& Ketelaar, 1991; Zelenski \& Larsen, 1999), if positive moods make people social, it follows that extraverts may get a greater sociability boost. That is, positive moods and extraversion may interact on sociability. The present research examined possible interactions between extraversion and mood condition on 
sociability.

In all three studies, participants were randomly assigned to a mood condition. Emotional films were used to induce mood to minimize demand characteristics (such as those of the VMIP) and the premise of the study was disguised as a study to examine personality preferences of films to further reduce demand characteristics (such as the additional demand effects of Cunningham, 1988b). Furthermore, each of the three current studies examined preferences for social and non-social situations while attempting to control for mood congruency effects.

Sociability was defined as the tendency to affiliate with others or a preference for being with others than to remain alone (Cheek \& Buss, 1981). The proposed changes in feeling social brought about by positive moods were not expected to be permanent or long-term. As such, the present research required a measure that enabled the assessment of sociability as a state.

Measuring Sociability

Despite instruments being specifically designed to measure sociability, such as the sociability scale (Cheek \& Buss, 1981), they assess sociability as a durable disposition or response tendencies (i.e., trait). As this research focuses on short-term changes in sociability, these standard measures of sociability are not appropriate for the purposes of this research without modification. Items included in the sociability scale include "I like to be with people" and "I prefer working with others rather than working alone." The phrasing of these items makes adaptation to state phrasing problematic. The International Personality Item Pool (IPIP) is a public domain of measures to assess individual differences. As many measures of individual differences are proprietary 
instruments, IPIP has created equivalent public domain measures. Items from social facets of personality scales and sociability components of temperament scales phrase items such that they are also more trait oriented. Furthermore, items are also worded in sentence structures that not only would require changes to tap the concept in a state manner but also make the necessary amendments problematic. For example, the IPIP sociability facet of the Hogan Personality Inventory contains items such as "love large parties" and "seek adventure", whereas the IPIP sociability facet of the California Psychological Inventory includes items like "start conversations" and "feel comfortable around people".

Despite extraversion not being identical to sociability, there are features that are common to both. Social characteristics are frequently measured as a component of the higher-order trait of extraversion (e.g., Eysenck Personality Questionnaire, Eysenck \& Eysenck, 1975). For example, descriptive adjectives used to describe and measure extraversion utilize social terms - talkative, withdrawn, shy, and quiet (note the latter three are reverse scored). Fortunately, there exists a measure of state extraversion. Fleeson et al. (2002) developed a list of adjectives that specifically explore the momentto-moment variations in extraverted behaviour. Thus, Fleeson et al.'s measure of state extraversion enables the exploration of sociability states following mood manipulations and thus, was used in all three studies. Participants rated each adjective on the extent that the adjective was descriptive of their current feelings. Thus, this measure assessed feeling extraverted as a way of exploring sociability. Furthermore, as individuals rated extraversion adjectives along with mood adjectives, this measure had the advantage of minimizing demand characteristics. 
Sociability was also assessed by examining preferences for social situations as sociability is defined as a preference to be with others than to remain alone. In all three studies participants reported their desire to be in social and non-social situations.

\section{The Three Studies}

Study 1 tested the link between mood differences and sociability (measured as feeling extraverted and as a preference for social situations). Recall that Cunningham (1988b) found socializing differences while using strong negative mood inductions relative to milder positive mood inductions. This initial study sought to conceptually replicate Cunningham's (1988b) findings, with stronger positive mood manipulations.

Study 2 mirrored Study 1 with two modifications. Study 2 employed a new positive mood manipulation film that was equal in length to the negative film. Additionally, a 'manipulation check' (Study 1B) revealed that the social and non-social situations differed in pleasantness (i.e., our items contained this common confound). Specifically, the social situations appeared more pleasant than the non-social situations. Thus, the findings of Study 1 could have been due to mood congruency. To address this possible confound, the sample situations from Lucas and Diener (2001) were used in Study 2.

Study 3 expanded on Studies 1 and 2, by adding a control condition to determine directionality of mood differences. Specifically, to more clearly determine if positive moods increased sociability or if negative moods decreased sociability. Additionally, a new measure of situations was developed to control for pleasantness of situations. Specifically, social and non-social situations were screened and selected such that they were equally balanced on pleasantness. 
Study 3 also extended Study 1 and 2 by incorporating a new feeling sociable scale. Adjectives that are linked to sociability (e.g., friendly) were added to the study so this could be assessed independently of the broader state extraversion scale. Furthermore, Study 3 broadened the scope of the research to behavioural measures of sociability (e.g., talkativeness defined as the total amount of talking time).

\section{Study 1}

This initial study explored the causal link between mood and sociability. Specifically, emotional films were used to induce mood, either a strong positive mood or a milder negative mood, and to reduce possible demand effects of prior research (recall Cunningham, 1988b).

\section{Hypotheses}

Hypothesis One. I hypothesize that people in the positive mood condition will report feeling more extraverted compared to people in the negative mood condition.

Hypothesis Two. As trait extraversion is linked to both pleasant affect and sociability, a regression analysis will be conducted to remove the variability associated with trait extraversion. I posit that the positive mood condition will be associated with feeling extraverted, compared to the negative mood condition, while simultaneously considering trait extraversion. If this is true, I will explore possible reactivity of extraverts on feeling extraverted through testing an interaction between mood and trait extraversion on feeling extraverted. That is, as extraverts react more strongly to the same positive mood stimuli and positive moods cause increases to feeling extraverted (hypothesis one and two) there exists the possibility that extraverts get a greater sociability boost from the positive mood induction. If the interaction is significant, the 
relationship is posited to be that extraverts will report feeling more extraverted relative to introverts and this will be magnified in the positive mood condition compared to the negative mood condition.

Hypothesis Three. I hypothesize that people in the positive mood condition will rate social situations as more desirable, compared to people in the negative mood condition. The ratings of non-social situations are not expected to differ by condition.

\section{Method}

Participants. Twenty-eight students participated in this study (6 male, 22 female) with equal numbers in the positive and negative mood conditions $(n=14$ in each condition). Students received course credit for participating.

\section{Materials}

Personality. Extraversion along with the other big five personality traits of openness, continuousness, neuroticism, and agreeableness were measured with Goldberg's Mini-Markers (Saucier, 1994). The Mini-Markers consist of 8 adjectives per trait, for a total of 40 items, rated on a seven point Likert response scale with high numbers representing strong agreement that the adjective was descriptive of the individual (see Appendix A). Cronbach alpha coefficients for self-ratings on this measure range between .78 and .90 for the different traits (Saucier, 1994).

Affect and Feeling Extraverted. This questionnaire assesses both moods and feeling extraverted with a total of 33 adjectives rated on a seven point Likert response scale, from 1 - Very Slightly or Not at all to 7 - Extremely or a lot (see Appendix B). Three different components of mood were calculated from this questionnaire: positive affect, negative affect, and pleasantness. Positive affect was created by taking the mean 
of Excited, Interested, Strong, Alert, and Active. Negative affect was created by the mean of Irritable, Upset, Nervous, Hostile, Distressed, and Jittery. Pleasantness was created by taking the mean of Pleased, Happy, Unhappy*, and $\mathrm{Sad}^{*}$. Items with an asterisk indicate reverse scored items.

Eleven adjectives assessed feeling extraverted (see Fleeson, et al. 2002). Feeling Extraverted was created by taking the mean of Energetic, Assertive, Talkative, Shy*, Bold, Quiet*, Adventurous, Extraverted, Withdrawn*, Bashful*, and Reserved*. Items with an asterisk indicate reverse scored items.

Situations. A new measure was developed to assess how much participants desired social and non-social situations. A total of twenty items were created to represent a variety of situations. Ten social situations (e.g., Eating dinner with a group of friends) and ten non-social situations (e.g., Going for a walk by yourself) were rated on a 7 point Likert type scale (from 1 - Very Slightly or Not at all to 7 - Extremely or a lot) to indicate how much do you want to do the following activities right now? (see Appendix C).

Films. The negative mood film was a three-minute clip from the movie "Signs" (Shyamalan, 2002) and shows a man arriving at a scene of an accident. He is told that his wife has been in the accident and she is pinned between a car and a tree. He is informed that this will be the last time he can talk to her before she dies. He and his wife say goodbye to each other.

The positive mood film was an 11-minute clip from the movie "Akeelah and the Bee" (Atchison, 2006) —an inspirational drama of an eleven-year-old girl from south Los Angeles who competes in the Scripps National Spelling Bee. She creates history in cowinning the event and in turn unites her neighbourhood, which witness the courage and 
inspiration of this amazing little girl.

Film Interest. A brief questionnaire was developed that asked how much participants liked the film clip, if they had seen it before, and if they would recommend the film to a friend (see Appendix D). Participants rated each question on a 5-point Likert type scale. This questionnaire was strictly to reinforce the premise of the study. Procedure

Participants were recruited for a study on film and personality. The experimental sessions were conducted with one to three participants per session. Following the informed consent, participants were each seated at a cubical with a computer and asked to complete the paper-and-pencil personality measures. They were then randomly assigned to either a positive or negative mood condition and asked to put on headphones and watch a film clip on the computer screen. The film interest questionnaire was then administered. This was followed by the affect, feeling extraverted, and situations questionnaires. Participants in the negative mood condition were asked to watch a second, positive film to repair the negative mood state, and all participants were debriefed.

\section{Results}

To determine if the films induced the appropriate mood, independent $t$-tests were conducted. Overall, there was a significant difference between the two conditions in positive affect $(d=1.16, t(26)=3.08, p<.01)$, negative affect $(d=1.62, \mathrm{t}(26)=-4.29, p$ $<.001)$ and pleasantness $(d=3.12, t(26)=8.27, p<.001)$ with the positive mood condition having higher levels of positive affect and pleasantness, and lower levels of negative affect (see Table 1 for means and standard deviations by condition). Therefore, 
it appears that the films created the appropriate mood differences.

Table 1

Comparison of Affective Terms by Mood Condition for Study 1.

\section{Condition}

\begin{tabular}{llllll} 
& \multicolumn{2}{c}{ Positive } & \multicolumn{2}{c}{ Negative } & \\
\cline { 2 - 5 } Affect & $M$ & $S D$ & $M$ & $S D$ & Cohen's $d$ \\
\hline Positive Affect & $4.56_{\mathrm{a}}$ & 1.16 & $3.40_{\mathrm{b}}$ & 0.80 & 1.16 \\
Negative Affect & $1.75_{\mathrm{a}}$ & 0.92 & $3.12_{\mathrm{b}}$ & 0.76 & 1.62 \\
Pleasantness & $6.05_{\mathrm{a}}$ & 0.64 & $3.36_{\mathrm{b}}$ & 1.04 & 3.12 \\
\hline
\end{tabular}

Note: means with different subscripts are different at least at the $p<.05$ level

To determine if feeling extraverted differed by condition, an independent t-test

was conducted. The results indicated that those in the positive mood condition $(M=4.23$, $S D=1.09)$ reported feeling more extraverted $(d=1.04, t(26)=2.77, p<.01)$ compared to those in the negative mood condition $(M=3.29, S D=0.66)$. Thus, hypothesis one was supported; people in the positive mood condition reported feeling more extraverted compared to people in the negative mood condition.

Trait extraversion and feeling extraverted are associated, both theoretically and empirically $(r=.33, p<.02)$. Furthermore, research has linked both trait extraversion and feeling extraverted (both as state extraversion and sociability) to pleasant affect. To determine if the positive mood condition is associated with feeling extraverted while considering trait extraversion $(M=4.14, S D=.95)$, a regression analysis was conducted on feeling extraverted with trait extraversion and condition (dummy coded) as predictors. Step 1 contains the trait extraversion score. Step 2 adds the condition variable. The $R^{2}$ change was $.26, p<.01$, partial $\eta^{2}=.56, d=1.19$ (see Step 2 of Table 2). This indicates 
that participants in the positive mood condition reported feeling more extraverted, compared to the negative mood condition, even while simultaneously considering trait extraversion. Thus, the data support hypothesis two; participants in the positive mood condition reported feeling more extraverted even when considering trait extraversion, which also predicted feeling extraverted.

Trait extraverts react more to positive mood inductions (Larsen, \& Ketelaar, 1991) and positive moods appear to be linked to feeling extraverted (hypothesis one was supported and Step 2 of the regression was also significant). Therefore, it is possible that trait extraverts get a greater boost of feeling extraverted in the positive mood condition. To explore this possible interaction between mood condition and trait extraversion on feeling extraverted, an interaction term (cross product of trait extraversion by condition) was computed. Step 3 includes the cross product term. There was a significant interaction between mood condition and trait extraversion $\left(\mathrm{R}^{2}\right.$ change $=.10$, partial $\eta^{2}=.42, d=.66$, $p=.04$, see Step 3 of Table 2). The nature of the interaction is such that the positive mood condition has a steeper positive slope compared to the negative mood condition slope. The positive slopes indicate that extraverts reported feeling more extraverted, relative to introverts. The form of the interaction suggests that extraverts reported a greater boost in feeling extraverted in the positive mood condition relative to the negative mood condition (see Figure 2). This aligns with the reactivity of extraverts and with the hypothesized form of interaction. 
Table 2

Regression Analyses for Trait Extraversion, Condition and their Interaction on Feeling Extraverted for Study 1.

\begin{tabular}{|c|c|c|c|c|c|}
\hline Step and Variable & B & SE B & $\beta$ & $t$ & $R^{2}$ \\
\hline \multicolumn{6}{|l|}{ Step 1} \\
\hline Trait Extraversion & .37 & .17 & .40 & $2.13^{*}$ & $.16^{*}$ \\
\hline \multicolumn{6}{|l|}{ Step 2} \\
\hline Trait Extraversion & .45 & .16 & .48 & $2.99 * *$ & \\
\hline Condition & .90 & .28 & .52 & $3.22 * *$ & $.42 * *$ \\
\hline \multicolumn{6}{|l|}{$\begin{array}{l}\text { Step } \\
3\end{array}$} \\
\hline Trait Extraversion & .09 & .22 & .10 & 0.41 & \\
\hline Condition & -1.67 & 1.21 & -.96 & -1.38 & \\
\hline Condition $\mathrm{x}$ Trait $\mathrm{E}$ & .62 & .28 & 1.50 & $2.18^{*}$ & $.52 * *$ \\
\hline
\end{tabular}

$* p<.05 ; * * p<.01$

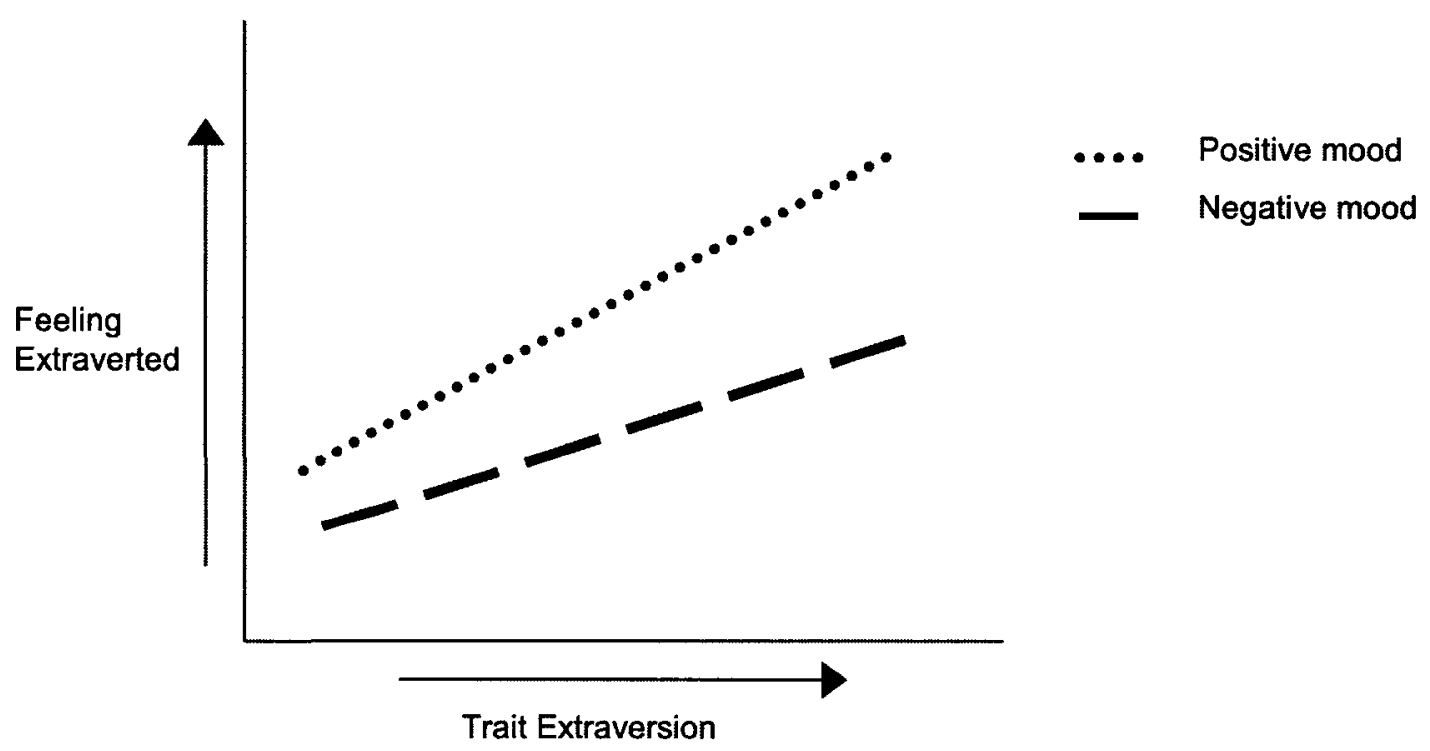

Figure 2. Feeling extraverted as a function of trait extraversion and mood condition. 
To determine if social situations were rated as more desirable by people in the positive mood condition, compared to people in the negative mood condition, a t-test was conducted. People in the positive condition $(M=3.73, S D=1.04)$ rated social situations as more desirable than people in the negative mood condition $(M=2.93, S D=0.86, d=$ $0.87, t(26)=2.22, p<.05)$. Therefore, results support hypothesis three; people in the positive mood condition desired social situations more than people in the negative mood condition. To determine if the non-social situations were rated differently by mood condition, a second t-test was conducted. Results indicated that non-social situations were rated similarly by people in the positive $(M=3.09, S D=0.89)$ and negative mood conditions $(M=3.25, S D=1.40, d=0.14, t(26)=-0.35, p>.50)$. Thus, in alignment with the prediction, non-social situations were rated equally desirable for the two mood conditions.

\section{Discussion}

Study 1 found that people in the positive mood condition reported feeling more extraverted, and indicated a stronger preference for social situations, compared to people in the negative mood condition. Additionally, mood condition predicted feeling extraverted after considering the trait extraversion relationship. This suggests that positive moods may indeed increase sociability. These findings align with the prior research while removing a demand effect. Furthermore, the stronger positive, relative to negative, mood induction provides additional support for Cunningham's (1988a) conclusion that positive moods cause increases in sociability. Moreover, an interaction between mood and trait extraversion was found such that extraverts had a larger sociability boost compared to introverts in the positive mood condition. 
Despite the findings of participants in the positive mood condition desiring more social situations, it is also possible, based on the mood congruency theory, that the findings are due to the pleasantness of the social situations (i.e., those in positive moods desiring more positive situations generally, and not necessarily the social aspect of the situations). To examine if the social situations were more pleasant than the non-social situations, Study 1B was conducted.

Study 1B

As social situations are generally more pleasant than the non-social situations (c.f., Lucas \& Diener, 2001), Study 1B was conducted to explore the pleasantness of the situations used in Study 1.

The rating scale of the situations questionnaire from Study 1 was changed from participants rating desire to participants rating pleasantness of the situations (the situations remained identical to Study 1). The protocol was consistent to Study 1 but the situations questionnaire was administered prior to any films. A total of 9 participants completed this study.

Results showed that social situations $(M=4.57, S D=0.60)$ were rated marginally more pleasant $(d=0.38, t(8)=-1.87, p<.10)$ than non-social situations $(M=4.37, S D=$ 0.43). There is a moderate difference, as noted by Cohen's effect size, with the social situations rated as more pleasant than the non-social situations.

These results revealed that the social situations used in Study 1 were moderately more pleasant than the non-social situations. In other words, sociability was confounded with pleasantness. Therefore, the higher desirability ratings of social situations in the positive mood condition may be due to participants desiring to be social, or it may be due 
to participants desiring to be in similarly positive situations in alignment with mood congruency effects.

\section{Study 2}

Study 2 replicates Study 1 with two adjustments. Study 1 employed a longer positive mood induction compared to the negative mood induction film. This tested whether or not Cunningham's (1988a) findings could be conceptually replicated but with stronger positive, relative to negative, mood inductions. However, this also created a time confound, and it was addressed in Study 2.

More importantly, Study 1B confirmed that my social situations were rated moderately more pleasant than the non-social situations. Therefore, Study 1, similar to Cunningham (1988b), had a confound of pleasantness for the social and non-social situations. To address this, a different situations questionnaire that groups situations into four categories of pleasantness, was used in Study 2 .

\section{Hypotheses}

Hypothesis One. I hypothesize that people in the positive mood condition will report feeling more extraverted compared to people in the negative mood condition.

Hypothesis Two. As trait extraversion is linked to both pleasant affect and sociability, a regression analysis will be conducted to remove the variability associated with trait extraversion. I posit that the positive mood condition will be associated with feeling extraverted, compared to the negative mood condition, while simultaneously considering trait extraversion. If this is true, I will explore the possible reactivity of extraverts on feeling extraverted through testing an interaction between mood and trait extraversion on feeling extraverted. That is, as extraverts react more strongly to the same 
positive mood stimuli and positive moods cause increases to feeling extraverted (hypothesis one and two) there exists the possibility that extraverts get a greater sociability boost from the positive mood induction. If the interaction is significant, the relationship is posited to be that extraverts will report feeling more extraverted relative to introverts and this will be magnified in the positive mood condition compared to the negative mood condition.

Hypothesis Three. I hypothesize that people in the positive mood condition will rate social situations as more desirable, compared to people in the negative mood condition. The ratings of non-social situations are not expected to differ by condition.

\section{Methods}

Participants. Forty-six students participated in this study (10 male, 36 female) with $n=26$ in the positive condition and $n=20$ in the negative mood condition. Participants received course credit for their participation. Materials

The trait, and affect and feeling extraverted measures are identical to Study 1.

Situations. The items were selected from Lucas and Diener's (2001) sample situations. Items selected for this questionnaire were equally balanced between social and non-social situations and taken to represent the different levels of pleasantness (pleasant, moderately pleasant, moderately unpleasant, and unpleasant) as categorized by Lucas and Diener (2001) based on student ratings. A total of twenty items were rated on a seven point Likert response scale (from 1 -Very Slightly or Not at all to 7 - Extremely or a lot) asking participants how much they think they would enjoy the particular situation at the moment (see Appendix E). ${ }^{2}$ 
Films. The 3-minute negative mood film clip "Signs" (Shyamalan, 2002) from Study 1 was used again in Study 2. The positive mood film was a short cartoon called "For the Birds" (Eggleston, 1986), and is also approximately 3 minutes in length. It depicts a flock of small birds who one by one perch on a telephone wire. Sitting close together has problems, and then comes a large dopey bird that tries to join them. The birds of a feather cannot help but make fun of him—and the clique mentality proves embarrassing in the end.

\section{Procedure}

The procedure for Study 2 was identical to Study 1 . The difference between the two studies was the films used to induce moods and the situations questionnaire.

\section{Results}

To determine that the films induced the appropriate mood differences, independent $t$-tests were conducted. Overall, there was a significant difference between the conditions for positive affect $(d=0.70, t(44)=2.35, p<.05)$, negative affect $(d=$ $1.08, t(44)=-3.64, p<.001)$ and pleasantness $(d=2.39, t(44)=8.05, p<.001)$ with people in the positive mood condition reporting higher levels of positive affect and pleasantness and lower levels of negative affect (see Table 3 for means and standard deviations by condition). Therefore, despite the reduced time of the positive mood clip, it appears that the films created the desired mood differences. 
Table 3

Comparison of Affective Terms by Mood Condition for Study 2.

\section{Condition}

Affect

Positive Affect

Positive

Negative

\begin{tabular}{llll}
\hline$M$ & $S D$ & $M$ & $S D$
\end{tabular} Cohen's $d$

\begin{tabular}{lllll}
\hline $4.02 \mathrm{a}$ & 0.87 & $3.38_{\mathrm{b}}$ & 0.95 & 0.70
\end{tabular}

Negative Affect

$1.92 \mathrm{a}$

0.82

$2.90_{\mathrm{b}}$

1.02

1.08

Pleasantness

$5.67_{\mathrm{a}}$

1.06

$3.00_{b}$

1.19

Note: means with different subscripts are different at least at the $p<.05$ level

To determine if feeling extraverted differed by condition, an independent t-test was conducted. The results indicated that those in the positive mood condition $(M=4.31$, $S D=0.95)$ reported feeling more extraverted $(d=0.66, t(44)=2.20, p<.05)$ compared to those in the negative mood condition $(M=3.73, S D=0.76)$. Thus, in agreement with Study 1, hypothesis one was supported; people in the positive mood condition reported feeling more extraverted compared to the negative mood condition.

Again, to determine if the positive mood condition is associated with feeling extraverted while considering trait extraversion $(M=4.57, S D=.86)$, a regression analysis was conducted on feeling extraverted with trait extraversion and condition (dummy coded) as predictors. Step 1 contains the trait extraversion score. Step 2 adds the condition variable. The $R^{2}$ change was $.11, p<.05$, partial $\eta^{2}=.34, d=0.70$ (see Step 2 of Table 4). This indicates that participants in the positive mood condition reported feeling more extraverted, compared to the negative mood condition, even while simultaneously considering trait extraversion. Thus, the data support the hypothesis that participants in the positive mood condition reported feeling more extraverted even when 
considering trait extraversion, which also predicted feeling extraverted.

Trait extraverts react more to positive mood inductions (Larsen, \& Ketelaar, 1991) and positive moods appear to be linked to feeling extraverted (hypothesis one was supported and Step 2 of the regression was also significant). Therefore, it is possible that trait extraverts get a greater boost of feeling extraverted in the positive mood condition. To explore this possible interaction between mood condition and trait extraversion on feeling extraverted, an interaction term (cross product of trait extraversion by condition) was computed. Step 3 includes the cross product term. There was not a significant interaction between mood condition and trait extraversion $\left(R^{2}\right.$ change $<.001$, partial $\eta^{2}=$ $.02, p=.89$, see Step 3 of Table 4). Therefore, disposition and mood condition did not interact to predict feeling extraverted.

Table 4

Regression Analyses for Trait Extraversion, Condition and their Interaction on Feeling Extraverted for Study 2.

\begin{tabular}{|c|c|c|c|c|c|}
\hline Step and Variable & B & SE B & $\beta$ & $T$ & $R^{2}$ \\
\hline \multicolumn{6}{|l|}{ Step 1} \\
\hline Trait Extraversion & .35 & .15 & .33 & $2.34^{*}$ & $.11^{*}$ \\
\hline \multicolumn{6}{|l|}{ Step 2} \\
\hline Trait Extraversion & .36 & .14 & .34 & $2.51^{*}$ & \\
\hline Condition & .59 & .25 & .32 & $2.40^{*}$ & $.22 * *$ \\
\hline \multicolumn{6}{|l|}{$\begin{array}{l}\text { Step } \\
3\end{array}$} \\
\hline Trait Extraversion & .33 & .24 & .31 & 1.41 & \\
\hline Condition & .39 & 1.39 & .22 & .28 & \\
\hline Condition $\mathrm{x}$ Trait $\mathrm{E}$ & .04 & .30 & .11 & .15 & $.22 *$ \\
\hline
\end{tabular}

To determine if social situations were rated as more desired by people in the 
positive mood condition compared to people in the negative mood condition, a t-test was conducted. People in the positive condition $(M=3.25, S D=0.68)$ rated social situations similarly compared to people in the negative mood condition $(M=3.27, S D=0.67), d=$ $0.02, t(44)=-0.07, p>.50)$. Therefore, results fail to support hypothesis three; people in the positive mood condition did not report desiring social situations more than people in the negative mood condition. ${ }^{3}$ To explore differences in desiring non-social situations by condition, a second t-test was conducted. Results indicated that people rated non-social situations similarly in the positive $(M=2.98, S D=0.83)$ and negative mood conditions $(M=3.31, S D=0.96, d=0.38, t(44)=-1.26, p>.20)$. Thus, in alignment with the prediction, non-social situations were rated similarly by people in the two mood conditions.

\section{Discussion}

Study 2 tried to replicate the findings of Study 1 while removing two confounds: film length with valence, and pleasantness of social versus non-social situations. The results of Study 2 are mixed in supporting the notion that positive moods increase sociability. The t-test and regression analysis showed stronger feelings of extraversion in the positive mood condition compared to the negative mood condition. However, there were no mood differences found in situational preferences.

In support of the broaden-and-build theory (Fredrickson, 1998, 2001), participants in the positive mood condition reported feeling more extraverted (social) than those in the negative mood condition. Furthermore, the positive mood condition predicted feeling extraverted even when considering trait extraversion. Although these results occurred in both studies, the differences in effect sizes are noteworthy. Specifically, Study 1 had a 
larger effect size $(d=1.20)$ compared to Study $2(d=0.70)$. Additionally, the differences in affect between the mood conditions were greater for Study 1 as indicated by their larger Cohen's $d$ (see Tables 1 and 3). Therefore, it appears that the greater mood differences are associated with greater differences in feeling extraverted.

The larger effect sizes for affect in Study 1 are most probably due to the difference in length of film clips. Study 1 used an 11-minute positive clip compared to the 3-minute clip used in Study 2. It is probable that the length of the film impacted the intensity of the mood induction.

An equally promising explanation for the larger effect sizes of Study 1 is the differences in content of the films. Some participants in Study 2 mentioned that they felt badly for the dopey bird in the positive film. Therefore, the positive mood induction in Study 2 may have induced both positive and negative emotions as positive and negative affect can co-occur at moderate levels (Watson, Clark, \& Tellegen, 1988). This notion is supported by the higher negative affect, and lower positive affect, and pleasantness scores in the positive mood conditions found in Study 2 compared to Study 1 (see Tables 1 and $3)$.

The results for social situations ratings were mixed between the two studies. Study 1 showed that participants in a positive mood rated social situations as more desirable compared to those in the negative mood condition. Unfortunately, social situations were also rated higher on pleasantness compared to non-social situations. Therefore, it is not possible to determine if the results are due to positive moods and sociability or positive moods and mood congruency effects. Study 2 did not find differences in ratings of enjoyment of social situations for mood condition. On the surface 
this seems like support for the mood congruency position. That is, after removing the pleasantness confound, the positive mood condition's preference for social situations seems to disappear. In other words, pleasantness, and not socialness, may explain the differences found in both Study 1 and Cunningham (1988b). However, the mood congruency position does not receive extensive support from Study 2 either. Mood congruence predicts that people in the positive mood condition would prefer pleasant situations (regardless of whether or not they were social), and this was not found in Study 2 either (see Appendix F). In other words, the null results in situation preferences are difficult to interpret with either theory.

It is noteworthy that some participants made comments regarding the situations used in Study 2, indicating that they had difficulty identifying or "seeing themselves" in the situations (e.g., playing water polo and we were ahead 4 to 0 ; talking on the phone to a lawyer; and sitting around the kitchen table with my friend struggling over our music assignment). Therefore, it is also possible that the lack of a difference in Study 2 is due to participants having difficulty identifying with the particular situations.

\section{Study 3}

Study 1 found that people in positive moods reported a preference for social situations, but this finding is inconclusive because of a confound (pleasantness). Study 2 did not show preferences for situations by mood. Therefore, situational preference due to mood remains unresolved. Studies 1 and 2 both suggest that people in a positive mood report feeling more extraverted relative to people in a negative mood. Furthermore, this was found while statistically controlling for trait extraversion. Although these findings are promising, the question of behaviour differences has not been addressed; specifically, 
if people in positive moods will actually behave more socially compared to people in other moods. Study 3 builds on Studies 1 and 2 with further improvements to assessment tools (e.g., situations questionnaire), and by adding assessments of actual social behaviour. In Study 3, participants again viewed film clips (to manipulate mood) and filled out questionnaires, but were also interviewed by an experimenter who used this interaction to assess social behaviour.

Study 3 differs from Study 1 and 2 in four key aspects. First, Study 3 adds a neutral condition. Study 1 and 2, through differing strengths in mood inductions, explored the directionality of positive moods increasing versus negative moods decreasing sociability. A more precise method to explore directionality is adding a neutral condition. The neutral condition allowed me to determine if positive moods are making participants feel more extraverted/social as opposed to the possibility that negative moods make participants feel less extraverted/social. Second, I added terms such as friendly and social to the feeling extraverted questionnaire, creating a separate measure of feeling sociable. Feeling extraverted (i.e., state extraversion) and being sociable, although similar, are not identical as extraversion is a broader construct. Therefore, to better explore the relationship between positive moods and sociability per se, this new measure of feeling sociable was added.

Third, a new measure of situational preference was created for this study to correct for the pleasantness confound and accessibility issues identified in previously used measures. This new measure was developed from a large pool of items. Items were identified by asking fellow students to list situations that were either pleasant or unpleasant. Items that were either frequently listed or appeared general and accessible to 
first year students were selected in phase 1. This larger selection of items was then prescreened on pleasantness and sociability. A final subset of accessible items was then selected so that sociability and pleasantness were not confounded.

Fourth, measures of social behaviour were added to the study. Although participants in the positive mood condition self-reported feeling more social, it does not necessarily mean that they will behave more socially. A structured interview was used as the social interaction to ascertain social behaviours. Schmidt and Fox (1995) have found that individuals who score high on sociability scales have also been rated as more talkative, friendly and sociable, by blind confederates during dyadic interactions. As such, the interviewer and a second researcher (both blind to condition) subjectively rated the sociability of each participant.

Social skills, behaviours that are positively reinforced by others, that have been identified as differing between people who socialize successfully versus unsuccessfully include total talking time, the number of times the individual initiated conversation, and the time elapse prior to responding (Eisler, 1976). Furthermore, Spitzberg, Brookshire, and Brunner (1990) identified eye contact, speaking rate, speaking fluency, and asking questions among others as essential features of proficient social behaviour. As such, the social behaviours assessed in Study 3 included the total amount of talking time (with and without pauses), the number of questions asked by the participant (as a form of initiating conversation), and a subjective rating of eye contact.

\section{Hypotheses}

Hypothesis One. In alignment with Studies 1 and 2, people in the positive mood condition will report feeling more extraverted compared to people in the negative mood 
and control conditions.

Hypothesis Two. People in the positive mood condition will report feeling more sociable compared to people in the negative mood and control conditions.

Hypothesis Three and Four. In alignment with Study 1 and Study 2, two regression analyses will be conducted to remove the variability associated with trait extraversion (one regression with feeling extraverted as the dependent variable and a second with feeling social as the dependent variable). I posit that the positive mood condition will be associated with feeling more extraverted/social, compared to the negative mood and control conditions, while simultaneously considering trait extraversion. If this is true, I will explore possible reactivity of extraverts on feeling extraverted/social through testing an interaction between mood and trait extraversion on feeling extraverted/social. If the interaction is significant, the relationship is posited to be that extraverts will report feeling more extraverted relative to introverts and this will be magnified in the positive mood condition compared to the negative mood condition.

Hypothesis Five. I hypothesize that people in the positive mood condition will rate social situations as more desirable, compared to people in the negative mood and control conditions. The ratings of non-social situations are not expected to differ by condition.

Hypothesis Six. People in the positive mood condition are expected to exhibit more social behaviours (such as longer speaking time, asking more questions, and greater eye contact), and be rated as more social compared to the negative mood and control conditions.

\section{Methods}


Participants. Participants were recruited through the first year psychology pool and received either course credit or ten dollars for participating. A total of 104 participants were recruited. Due to technical problems or lack of following instructions, the sample was trimmed to 99 participants ( 47 female, 52 male ${ }^{4}$ ). A computer program randomly assigned participants to condition resulting in 32 participants in both the positive and negative conditions and 35 in the control condition.

\section{Materials}

Affect and Feeling Extraverted/Sociable. The affective components of positive affect, negative affect and pleasantness were assessed the same as in Studies 1 and 2. Feeling extraverted was also consistent with Studies 1 and 2 and had a Cronbach alpha of .76 in Study 3. The adjectives of friendly, social, gregarious, approachable, impolite, and antisocial were added to this measure and rated on the seven point Likert scale (from 1 Very Slightly or Not at all to 7 - Extremely or a lot, see Appendix G). Feeling sociable was created by taking the mean of Talkative, Quiet*, Friendly, Social, Gregarious, Approachable, Impolite*, and Antisocial*. Items with an asterisk indicate reverse scored items. Multiple thesauruses were used to develop a list of synonyms for sociability. Items that tapped social aspects without obviously being a component of another big five trait (such as openness) were then selected to form the sociability scale. The feeling sociable scale had a Cronbach alpha of .75 .

Situations. This questionnaire was developed by the author to represent social and non-social situations. Items were generated by asking fellow students to list situations that were pleasant or unpleasant. Items that were either frequently listed or general (e.g., go to the museum) were then selected to form a large subset. Some items were edited for 
clarity to address social compared to non-social situations (e.g., go to the museum with $a$ group of friends). An on-line study screened a total of 82 items on a five point Likert scale for both pleasantness (from 1 -very pleasant to 5 -very unpleasant) and sociability of the situations (from 1 - very social to 5 - not at all social, see Appendix $\mathrm{H}$ ). Participants were recruited through first year psychology class and received $0.5 \%$ increase in final grade for their participation $(\mathrm{N}=57,19$ males and 39 females).

Items were selected by extreme scores on sociability (both high and low on the five point Likert scale) to represent the social $(M=1.83, S D=0.82)$ and non-social items $(M=4.51, S D=0.79)$. Items were then selected into two categories, pleasant and unpleasant situations. Items were balanced on sociability of situations between the pleasant and unpleasant situations (see Table 5 for means and standard deviations). Additionally, the pleasantness of the social and non-social situations was balanced $(d=$ $0.02, t(57)=-0.32, p>.50)$. A total of 20 items comprise the situations questionnaire to be used in Study 3 (see Appendix I). Participants rated, on a seven point Likert scale (from 1 -Very Slightly or Not at all to 7 - Extremely or a lot), how much they want to do the listed activities. 
Table 5

Means and Standard Deviations for Ratings of Pleasantness and Socialness for Situational Categories (Study 3).

\begin{tabular}{lccccccccc}
\hline & \multicolumn{3}{c}{ Pleasant Ratings of Situations } & \multicolumn{3}{c}{ Social Ratings of Situations } \\
\cline { 2 - 10 } Category & \multicolumn{2}{c}{ Social } & \multicolumn{2}{c}{ Non-Social } & \multicolumn{2}{c}{ Social } & \multicolumn{2}{c}{ Non-Social } \\
& $M$ & $S D$ & $M$ & $S D$ & $M$ & $S D$ & $M$ & $S D$ \\
\hline Pleasant & 1.42 & 0.12 & 1.41 & 0.15 & 1.72 & 0.19 & 4.51 & 0.25 \\
Unpleasant & 2.82 & 0.25 & 2.86 & 0.24 & 1.94 & 0.15 & 4.52 & 0.24 \\
\hline
\end{tabular}

Note: Very Pleasant $=1$, and Very Unpleasant $=5$; Very Social $=1$, Not at all Social $=5$.

Films. All films are approximately 11 minutes in length. The positive mood condition was a clip from "Akeelah and the Bee" (Atchison, 2006) as used in Study 1. The neutral mood condition viewed a clip from a roundtable discussion on Beowulf (Harryson, 2006). The topics discussed included "Is Beowulf a book?" and "Is it literature?" The negative mood condition viewed a clip from "Stepmom" (Columbus \& Levangie, 1998). In the clip, the mother is informed that the treatments for her cancer are not working and she is dying; she has a discussion with the new stepmother and celebrates Christmas with her two kids (saying goodbye to each of them as it will be her last Christmas). A computer program randomly selected the film so that the researcher was blind to condition.

Behaviour Appraisal. The researcher entered the room and asked a series of questions. The conversation was recorded to allow for coding of total talk time, the number of questions asked, and if any prompts were made. Questions included: "How 
frequently do you go to the movies?, What types of movies do you enjoy?, What is your favourite movie and why?, How much TV do you watch in a typical day and in a typical week?, What is your favourite TV show and why?"

Furthermore, subjective ratings of sociability were made (either immediately after the interview [for the interviewer] or via the sound recording [by a second researcher]). The interviewer also subjectively rated amount of eye contact during the interview period. Both subjective ratings were made on a 5-point Likert type scale.

\section{Procedure}

Upon arriving at the testing location, participants were asked to sit at a computer terminal and complete an informed consent document. Participants were then asked to complete the personality measure of Goldberg's Mini Markers. This was followed by instructions to put on headphones and watch the film on the computer screen in front of them (the researcher then left the room). A computer program randomly selected the film (positive, negative, or control) so the experimenter was blind to condition. At the end of the film, a screen was displayed asking participants to let the researcher know that the film had ended. A second questionnaire package, containing the film questionnaire (to continue the premise of the study), and the affect and social situation questionnaires, were then completed. The researcher then entered the room and asked a series of questions for the behavioural appraisal component of the study. A small voice recorder (MP3) was hung around the neck of the researcher to record the conversation (which was not evident). Participants were then asked to watch a second film to repair the negative mood induction. As the researcher was blind to condition, all participants watched the second film. Participants were then debriefed and permission was gained for keeping the 
voice recording.

\section{Results}

\section{Manipulation Check}

To determine if the films induced the appropriate mood differences, three ANOVAs on affect were conducted with condition as the independent variable. The omnibus tests were significant for positive affect $(F(2,96)=18.22, p<.001)$, negative affect $(F(2,96)=5.53, p=.005)$ and pleasantness $(F(2,96)=21.84, p<.001)$ indicating that at least one condition differed from another. To examine which groups differed, posthoc comparisons using Tukey's Honestly Significant Differences were employed. Positive affect and pleasantness differed between all three conditions whereas negative affect only differed for the negative mood induction compared to both positive and control conditions. See Table 6 for means and standard deviations by condition. The positive mood condition had the highest levels of positive affect and pleasantness whereas the negative mood condition had highest levels of negative affect. Therefore, it appears that the films induced the appropriate moods.

Table 6

Comparison of Affective Terms by Mood Condition for Study 3.

\begin{tabular}{lllllll}
\hline & \multicolumn{5}{c}{ Condition } \\
\cline { 2 - 7 } Affect & \multicolumn{2}{c}{ Positive } & \multicolumn{2}{c}{ Control } & \multicolumn{2}{c}{ Negative } \\
\cline { 2 - 7 } Positive Affect & $M$ & $S D$ & $M$ & $S D$ & $M$ & $S D$ \\
Negative Affect & $2.08_{\mathrm{a}}$ & 0.98 & $3.37_{\mathrm{b}}$ & 0.94 & $4.18_{\mathrm{c}}$ & 0.97 \\
Pleasantness & $5.70_{\mathrm{a}}$ & 0.95 & $2.18_{\mathrm{a}}$ & 0.92 & $2.79_{\mathrm{b}}$ & 1.03 \\
& & $4.88_{\mathrm{b}}$ & 0.85 & $3.91_{\mathrm{c}}$ & 1.40 \\
\hline
\end{tabular}

Note: means with different subscripts are different at least at the $\mathrm{p}<.05$ level with Tukey's Honestly Significant Difference 


\section{Feeling Extraverted and Feeling Sociable}

To determine if the positive mood condition was associated with higher ratings of feeling extraverted compared to both the negative and control conditions, an ANOVA was conducted on feeling extraverted with condition as the independent variable. The omnibus test revealed significant group differences for feeling extraverted $(F(2,96)=$ 5.46 , partial $\eta^{2}=.10, p=.006$ ). Post-hoc comparisons showed that the positive mood condition $(M=4.63, S D=0.70)$ differed from both the negative $(M=4.08, S D=0.82)$ and control conditions $(M=4.02, S D=0.89)$ which did not differ from each other. Therefore, hypothesis one is supported; people in the positive mood condition reported feeling more extraverted relative to people in the negative mood and control conditions.

To determine if the positive mood condition was associated with higher ratings of feeling sociable compared to both the negative and control conditions an ANOVA was conducted on feeling sociable with condition as the independent variable. The omnibus test revealed significant group differences for feeling sociable $\left(F(2,96)=5.13\right.$, partial $\eta^{2}$ $=.10, p=.008)$. Post-hoc comparisons showed that the positive mood condition $(M=$ $5.14, S D=0.72)$ differed from both the negative $(M=4.61, S D=0.83)$ and control conditions $(M=4.61, S D=0.74)$ which did not differ from each other. Therefore, hypothesis two is also supported; people in the positive mood condition reported feeling more sociable relative to people in the negative mood and control conditions.

Similar to Study 1 and 2, to determine if mood conditions explain feeling extraverted while controlling for the variability associated with trait extraversion $(M=$ $4.60, S D=.90$ ), a regression analysis was conducted on feeling extraverted with trait 
extraversion and condition (dummy coded) as predictors. Step 1 contains the trait extraversion score $(F(1,97)=8.18, p=.005)$. Step 2 adds the two condition variables.

The $R^{2}$ change was $.17, p<.001, d=.91$ (see Step 2 in Table 7) with $F(3,95)=10.28, p<$ .001 for the Step 2 model. Therefore, as predicted, condition explains a significant amount of variation in feeling extraverted while simultaneously considering trait extraversion.

In alignment with reactivity of extraverts, it is possible that extraverts get a greater boost of feeling extraverted in the positive mood condition. To explore an interaction between condition and feeling extraverted, interaction terms (cross products of trait extraversion by dummy coded condition variables) were computed and added as a Step 3 to the regression. The interaction was not significant for feeling extraverted $\left(R^{2}\right.$ 


$$
\text { change }=.02, d=.29, p=.35 \text {, see Step } 3 \text { in Table 7). }
$$

Table 7

Regression Analyses for Trait Extraversion, Condition, and their Interaction on Feeling Extraverted for Study 3.

\begin{tabular}{llllll}
\hline Step and Variable & $b$ & $S E b$ & $\beta$ & $T$ & $R^{2}$ \\
\hline $\begin{array}{l}\text { Step 1 } \\
\text { Trait Extraversion }\end{array}$ & .26 & .09 & .28 & $2.86^{* *}$ & $0.08^{* *}$ \\
Step 2 & & & & & \\
$\quad$ Trait Extraversion & .37 & .09 & .39 & $4.24^{* * *}$ & \\
$\quad$ Positive Mood & .77 & .19 & .43 & $4.12^{* * *}$ & \\
$\quad$ Negative Mood & .12 & .18 & .01 & 0.65 & $0.25^{* * *}$ \\
Step 3 Trait Extraversion & .39 & .13 & .42 & $3.11^{* *}$ & \\
$\quad$ Positive Mood & .14 & .98 & .08 & 0.14 & \\
$\quad$ Negative Mood & .98 & 1.01 & .54 & 0.97 & \\
$\quad$ Positive Mood x Trait E & .15 & .22 & .36 & 0.69 & \\
$\quad$ Negative Mood x Trait E & -.20 & .21 & -.55 & -0.96 & $0.26^{* * *}$ \\
\hline
\end{tabular}

${ }^{*} p<.05 ;{ }^{* *} p<.01 ;{ }^{* * *} p<.001$

To determine if mood conditions explain feeling sociable while statistically controlling for the variability of trait extraversion, a regression analysis was conducted on feeling sociable with trait extraversion and condition (dummy coded) as predictors. Step 1 contains the trait extraversion score $(F(1,97)=4.08, p=.05)$. Step 2 adds the two condition variables. The $R^{2}$ change was $.14, p<.001, d=.81$ (see Step 2 in Table 8) with $F(3,95)=7.18, p<.001$ for the Step 2 model. Therefore, as predicted, condition explains a significant amount of variability in feeling sociable while simultaneously considering trait extraversion.

Again, in alignment with the reactivity of extraverts, it is possible that extraverts get a greater boost of feeling sociable in the positive mood condition. To explore an 
interaction between condition and feeling sociable, interaction terms (cross products of trait extraversion by dummy coded condition variables) were computed and added as a Step 3 to the regression. The interaction was not significant for feeling sociable $\left(R^{2}\right.$ change $<.001, p=.79$, see Step 3 in Table 8).

Table 8

Regression Analyses for Trait Extraversion, Condition, and their Interaction on Feeling Sociable for Study 3.

\begin{tabular}{llllll}
\hline Step and Variable & $\mathrm{b}$ & $S E \mathrm{~b}$ & $\beta$ & $T$ & $R^{2}$ \\
\hline Step 1 & & & & & \\
\multicolumn{1}{c}{ Trait Extraversion } & .18 & .09 & .20 & $2.02^{*}$ & $0.04^{*}$ \\
Step 2 & & & & & \\
$\quad$ Trait Extraversion & .27 & .09 & .31 & $3.21^{* *}$ & \\
$\quad$ Positive Mood & .65 & .18 & .38 & $3.55^{* * *}$ & \\
$\quad$ Negative Mood & -.04 & .18 & -.02 & -0.23 & $0.19^{* * *}$ \\
Step 3 & & & & & \\
$\quad$ Trait Extraversion & .30 & .12 & .34 & $2.41^{*}$ & \\
$\quad$ Positive Mood & .52 & .96 & .31 & 0.54 & \\
$\quad$ Negative Mood & .52 & .99 & .30 & 0.52 & \\
$\quad$ Positive Mood x Trait E & .03 & .22 & .09 & 0.16 & \\
$\quad$ Negative Mood x Trait E & -.12 & .20 & -.34 & -0.57 & $.19^{* * *}$ \\
\hline
\end{tabular}

${ }^{*} p<.05 ;{ }^{* *} p<.01 ; p<.001$

\section{Situations}

To examine the rating of situations a 2 (social/non-social) $\times 2$

(pleasant/unpleasant) x 3 (mood conditions) repeated measures ANOVA was conducted. It was hypothesised that people in the positive mood condition would desire social situations over non-social situations. A three way interaction (socialness $\mathrm{x}$ pleasantness $\mathrm{x}$ condition) was marginally significant (Wilks' Lambda $=.95, F(2,96)=2.44, p=.09)$ and 
there was a significant two way interaction (socialness $\mathrm{x}$ condition; Wilks' Lambda $=.92$, $F(1,96)=4.24, p=.02)$. The form of the significant two way interaction was that people in the positive mood condition desired social situations over non-social situations, people in the negative mood condition desired non-social situations over social situations, and people in the control condition have a slight preference for non-social situations over social situations (see Figure 3 for the significant two-way interaction). Therefore hypothesis five is supported; people in the positive mood condition desired social situations over non-social situations. The marginally significant three-way interaction suggests that the situational preferences in positive and negative mood conditions does not depend on the pleasantness of the situation. However, people in the control condition prefer non-social over social situations when they are pleasant, but prefer social over nonsocial situations when they are unpleasant. That is, for the control condition, doing something enjoyable is better alone, whereas having company is better if the task is unpleasant (see Figures 4 and 5 for the marginally significant three way interaction).

The main effect for pleasantness of the situations was significant $(F(1,96)=3.19$, $p<.001)$ with more pleasant situations being more desired. No other aspects were significant (see Table 9): main effect for socialness of the situations $(F(1,96)=0.03, p=$ $.85)$, the interaction between pleasantness and socialness $(F(1,96)=1.34, p=.25)$ and the interaction between pleasantness and condition $(F(2,96)=0.81, p=45)$.

To explore the possible reactivity of extraverts, a second ANOVA was conducted with trait extraversion (mean split) added to the model. Trait extraversion was not significant $(F(1,93)=0.18, p=.68)$ nor was the interaction of condition by trait extraversion $(F(1,93)=0.75, p=.48)$. 


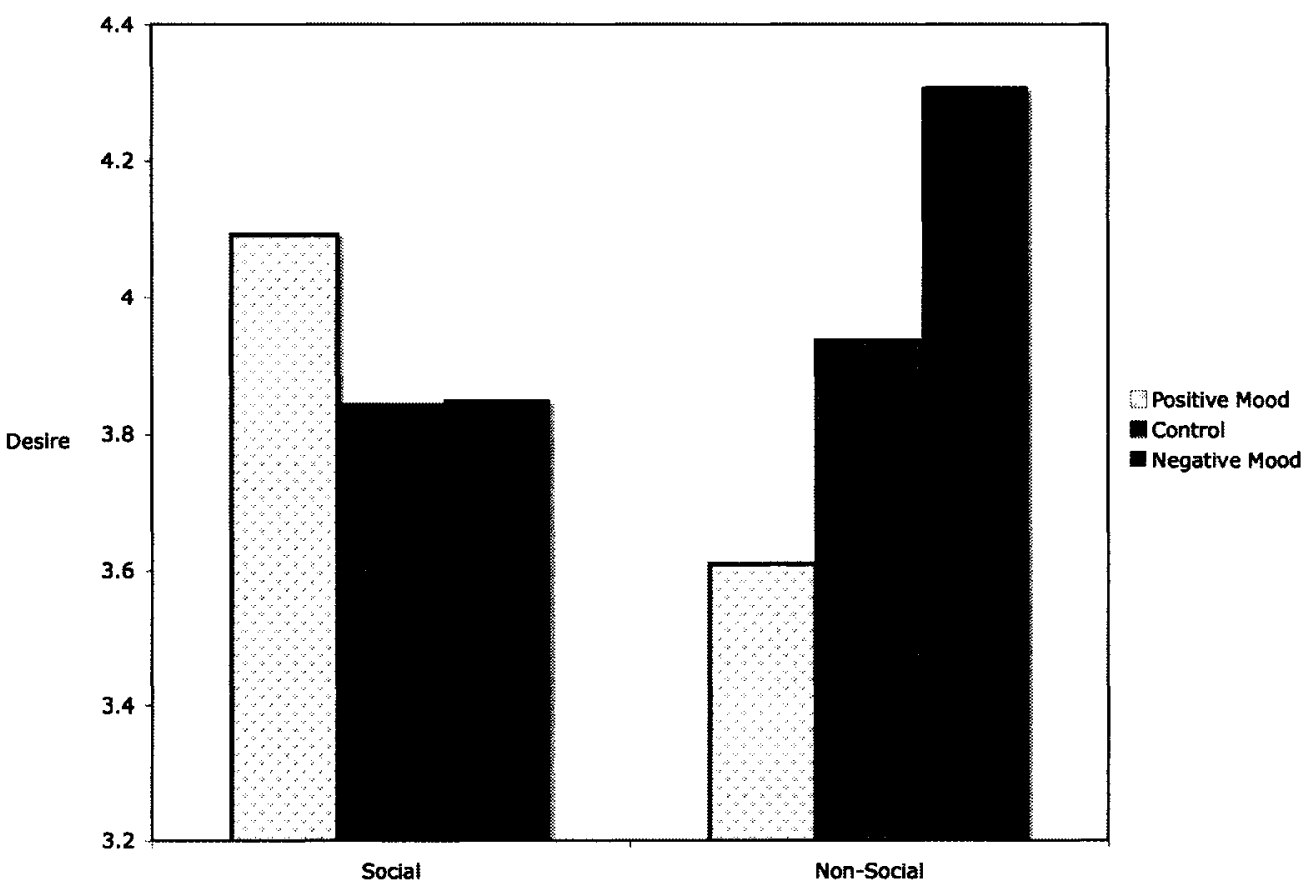

Figure 3. Rating of desire for situation for mood condition by socialness interaction (Study 3).

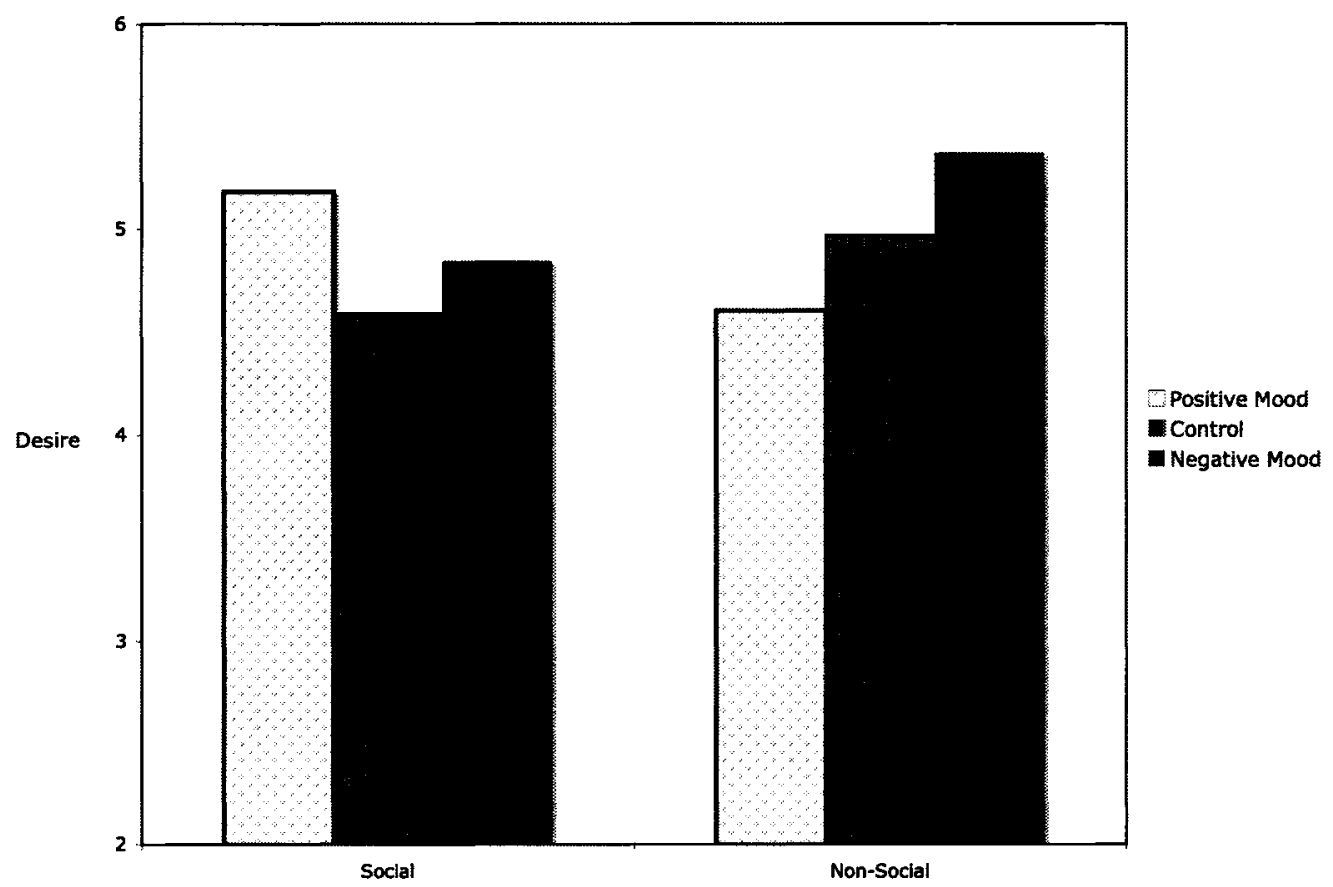

Figure 4. Rating of desire for situation for mood condition by socialness interaction for pleasant situations (Study 3). 


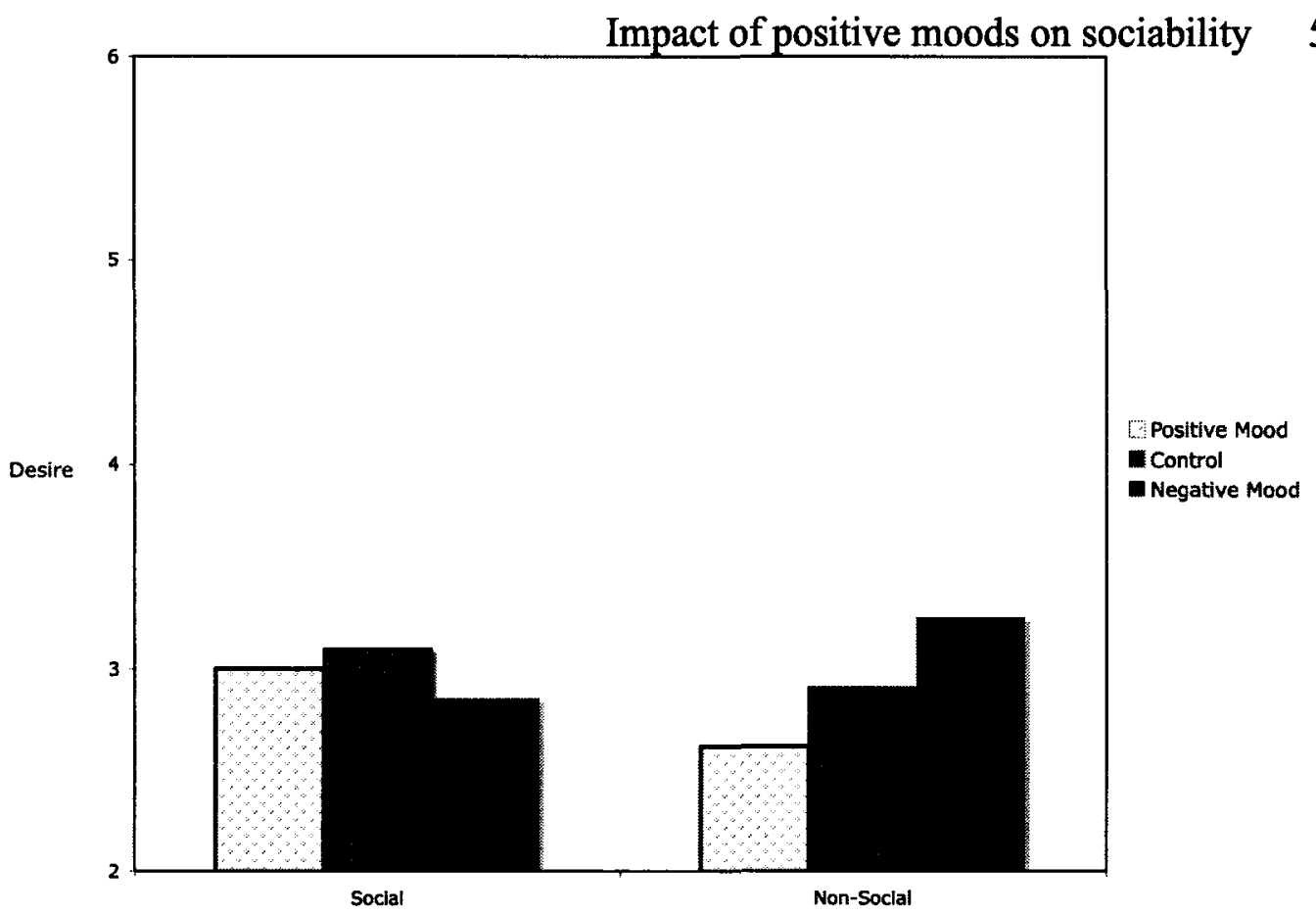

Figure 5. Rating of desire for situation for mood condition by socialness interaction for unpleasant situations (Study 3).

Table 9

Repeated Measures ANOVA results for Socialness $x$ Pleasantness $x$ Condition.

\begin{tabular}{lrrrrrr}
\hline Source & $S S$ & $d f$ & $M S$ & $F$ & $p$ & Partial $\eta^{2}$ \\
\hline Socialness & 0.06 & 1 & 0.06 & 0.03 & .85 & 0.00 \\
Socialness * Condition & 14.41 & 2 & 7.20 & 4.24 & .02 & 0.08 \\
Error (Socialness) & 163.03 & 96 & 1.70 & & & \\
Pleasantness & 383.35 & 1 & 383.35 & 319.17 & $<.001$ & 0.77 \\
Pleasntness * Condition & 1.95 & 2 & 0.98 & 0.81 & .45 & 0.02 \\
Error (Pleasantness) & 115.30 & 96 & 1.20 & & & \\
Socialness * Pleasantness & 0.68 & 1 & 0.68 & 1.34 & .25 & 0.01 \\
Socialness * Pleasantness * & 2.48 & 2 & 1.24 & 2.44 & .09 & 0.05 \\
Condition & & & & & & \\
Error (Socialness * & 48.72 & 96 & 0.51 & & & \\
Pleasantness) & & & & & & \\
\hline
\end{tabular}




\section{Behaviour Ratings}

Eye contact. An ANOVA was conducted on eye contact with condition as the independent variable. It showed no difference in ratings of eye contact between the three conditions $\left(F(2,96)=0.82\right.$, partial $\eta^{2}=.02, p=.45$ (see Table 10 for means and SD).

Socialness. The inter-rater correlation was large and significant $(r=.64, p<.001)$ with $93 \%$ percent of scores being rated within 1 point. An ANOVA was conducted on the average of the two raters' scores of socialness with condition as the independent variable. An ANOVA showed no difference in experimenter ratings of socialness between the three conditions $\left(F(2,96)=0.06\right.$, partial $\eta^{2}<.01, p=.94$ (see Table 10 for means and $\mathrm{SD})$.

Talking time. Three separate ANOVAs were run on slightly different aspects of talking time by condition. The first ANOVA examined overall speaking time (with pauses), the second examined speaking time without pauses, and the third examined the difference between with and without pauses. The null hypothesis failed to be rejected in all three ANOVAs $\left(F(2,89)=.01\right.$, partial $\eta^{2}<.01, p=.99 ; F(2,89)=.17$, partial $\eta^{2}<.01$, $p=.85 ; F(2,89)=.06$, partial $\eta^{2}<.01, p=.93$ for the respective ANOVAs).

Asking Questions. The number of questions asked by the participant was coded and entered into an ANOVA with condition as the independent variable. The range in number of questions asked was zero to a maximum of seven. The null hypothesis failed to be rejected $\left(F(2,89)=.02\right.$, partial $\left.\eta^{2}<.01, p=.98\right)$. In sum, no significant differences between mood conditions were found in behavioural indicators of sociability. 
Table 10

Comparison of Observer Ratings and Speaking Times by Mood Condition (Study 3).

\begin{tabular}{llllllc}
\hline & \multicolumn{7}{c}{ Condition } \\
\cline { 2 - 7 } Affect & \multicolumn{2}{c}{ Positive } & \multicolumn{2}{c}{ Control } & \multicolumn{2}{c}{ Negative } \\
\cline { 2 - 7 } & $M$ & $S D$ & $M$ & $S D$ & $M$ & $S D$ \\
\hline Eye Contact & 2.69 & 1.09 & 3.00 & 1.14 & 2.75 & 0.95 \\
Mean Social Rating & 3.17 & 0.95 & 3.2 & 0.87 & 3.25 & 0.98 \\
Total Speaking Time (with pauses & 80 & 41 & 79 & 31 & 79 & 39 \\
in seconds) & & & & & & \\
Speaking Time (without pauses in & 50 & 24 & 47 & 17 & 49 & 20 \\
seconds) & & & & & & \\
Difference between Total & 30 & 22 & 32 & 23 & 30 & 24 \\
Speaking time (with minus & & & & & & \\
without pauses) & & & & & & \\
Questions & 1.00 & 1.64 & 1.03 & 0.98 & 1.06 & 1.09 \\
\hline
\end{tabular}

\section{Exploring Sociability Measures}

To explore the relationships between the different measures of sociability, bivariate correlations were conducted (see Table 11). Trait extraversion was associated with both feeling extraverted and the average of the researchers subjective rating of sociable behaviour. Feeling sociable was associated with eye contact, mean rating of social behaviour, and talk time (without pauses). Therefore, although people reporting feeling more sociable in the positive mood condition, and feeling sociable was associated with other measures of social behaviour, the other measures of social behaviour did not differ significantly by condition.

To explore the reactivity of extraverts additional ANOVAs were conducted with trait extraversion (mean split) added to the models. None of the condition $\mathrm{x}$ trait 
extraversion interaction terms were significant on the behavioural measures (mean social rating, eye contact, talking time, questions asked). 


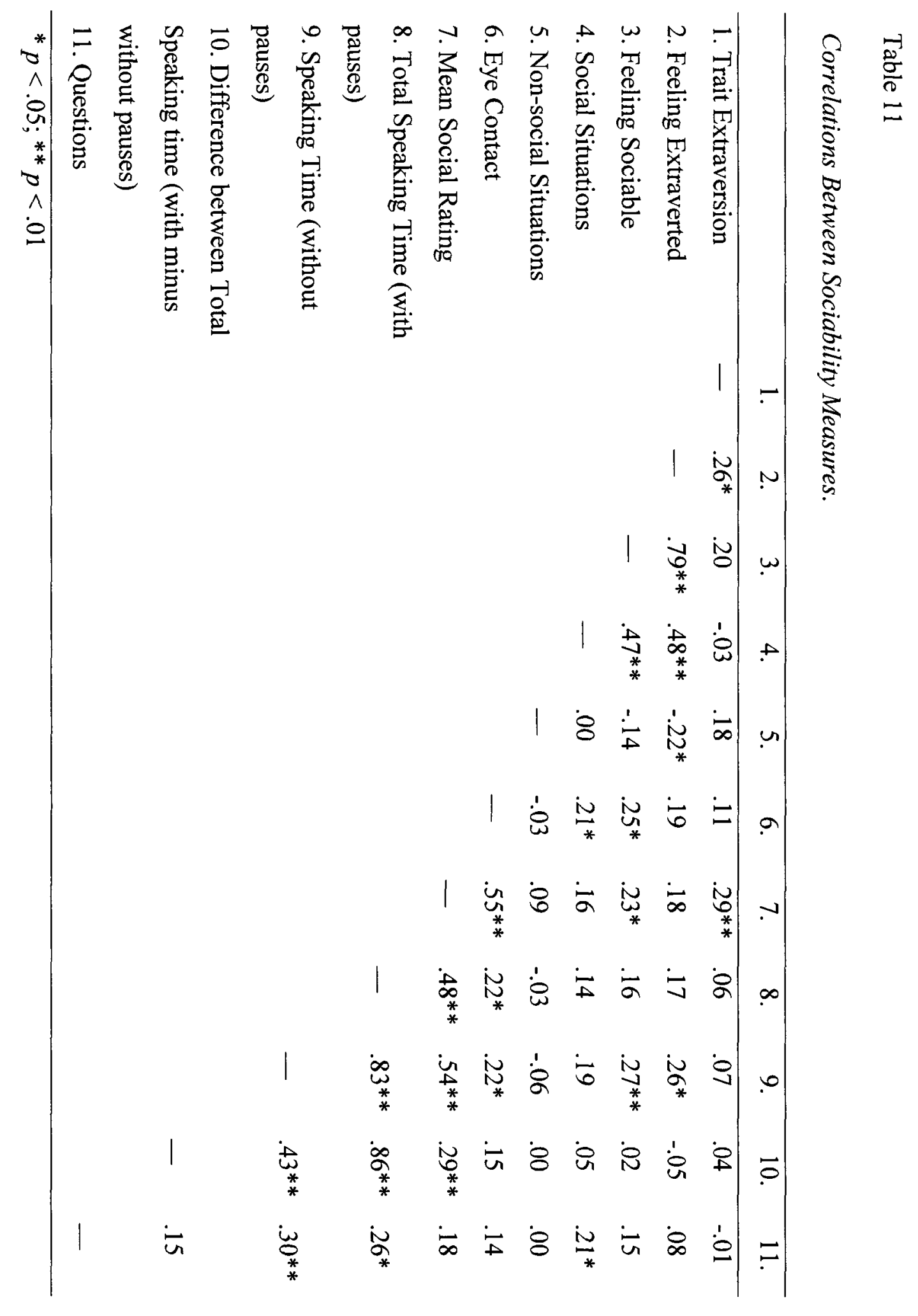

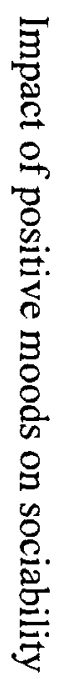




\section{Discussion}

The goal of this study was to assess whether or not positive moods increase sociability. Study 3 expanded on Studies 1 and 2 by including a broader self-report measure of feeling sociable and a social interaction component. Furthermore, Study 3 employed a new questionnaire to assess preference for social and non-social situations in an attempt to clarify the situational results of Studies 1 and 2. Additionally, Study 3 expanded on determining directionality implication of mood on sociability by including a control condition. Although the results are somewhat mixed, positive moods do appear to increase at least some aspects of sociability.

In alignment with Studies 1 and 2, positive moods were associated with feeling more extraverted in Study 3. The results for the new feeling sociable scale (which includes additional social adjectives while removing specific non-social extraverted adjectives) mirror the trends of the feeling extraverted scale. As the broader concept of trait extraversion is argued to include positive affect as a fundamental feature, it could have been argued that the findings of people feeling more extraverted in the positive mood condition with Study 1 and Study 2 were due to the positive affective component of extraversion and not necessarily due to the sociability component of extraversion. For this reason the findings of feeling sociable mirroring the trends of feeling extraverted are important as it refutes this reasoning.

Furthermore, the inclusion of the neutral condition allows me to establish the effects of positive mood independently of negative mood. Specifically, the self-report results demonstrate that positive moods increase feelings of sociability and extraversion 
as the positive mood condition differed from the control condition. Furthermore, these trends held when simultaneously considering trait extraversion.

The situation selection data showed that people in the positive mood condition preferred social situations over non-social situations and this pattern held for both pleasant and unpleasant situations. Therefore, not only is there support for people in positive moods desiring more social situations, but this effect is not attributable to mood congruency. That is, the situations selected for inclusion in Study 3 were balanced in pleasantness. The preferences for social situations found in Study 3 are due to the social aspect of the situation and not the pleasantness. Therefore, positive moods seem to make people feel sociable and desire more social situations.

Furthermore, although pleasant situations were preferred over unpleasant situations, the interaction between pleasantness and mood condition was not significant. Mood congruency theory would predict that positive moods would have a preference for pleasant situations, relative to a negative mood condition. Similarly, the negative mood condition would show preference for unpleasant situations, relative to a positive mood condition. Study 3 found that positive and negative moods and control conditions rated pleasant situations similarly. Likewise, unpleasant situations were also rated similarly by the three mood conditions. This is clearly indicated by the lack of interaction between pleasantness and mood conditions. Thus, mood congruency effects were not found.

Alternatively, the data is mixed when considering negative mood effects on sociability. When examining feeling extraverted and feeling social scales, the neutral and negative mood conditions do not differ. Therefore, it would appear that negative moods do not necessarily make people less social. However, when examining the situational 
results, people in the negative mood condition desire non-social situations regardless of pleasantness and more so than people in the neutral condition. This would suggest that negative moods decrease the desire to socialize. Recall that discrete emotions are seen as narrowing thought and action. Social situations can be perceived as requiring a broadening of attention, relative to non-social situations, in that people can be introspective while alone whereas in social situations attention needs to be directed to external sources such as conversations. It appears that negative moods seem to decrease the desire to socialize, but do not make people less social.

Interestingly, despite people in positive moods self-reporting feeling more sociable, no differences were found between the conditions for actual behaviours related to sociability (e.g., eye contact, or talkativeness). Furthermore, the subjective rating of sociability by the researchers did not differ between the conditions. Therefore, although people endorsed social adjectives as being more self-descriptive when in positive moods, it was not reflected in the behaviours or impressions measured in Study 3. This contrasts with Cunningham's (1988a) findings of people in positive moods talking more and revealing more of themselves compared to those in the negative mood condition. A few possibilities exist for the discrepancies in findings.

First, the social interaction of interviewer-interviewee is quite formal and structured. As the majority of individuals' social behaviour is influenced by social norms (Eisler, 1976), it is possible that rigid norms for the interaction dictated behaviour. Despite variability in the behavioural measures assessed, it is possible that the variability was primarily due to cultural and individual differences, such as the personality trait of openness. The norms of the formal situation may not have been conducive to eliciting the 
behavioural responses that participants may have been feeling. Second, the social interactions themselves were short (lasting on average only a few minutes). It is possible that a longer social interaction is needed to see behavioural differences due to mood. Third, the social behaviours examined may be poor as they were only weakly correlated with feeling social. It is possible that different measures of social behaviours, such as tone of voice, body language, and number of spoken words, could have detected differences in socializing due to mood. Cunningham (1988a) found behavioural differences, specifically increased levels of self-disclosure, for positive compared to negative moods. It is possible that assessing self-disclosure in Study 3 may have revealed mood differences.

Alternatively, there may not be differences in social behaviour due to mood. The possibility exists that positive moods can influence the decision to enter a social situation without actually altering behaviour in the situation. That is, positive moods may foster the preference for social situations while the behaviour elicited within the situation would remain consistent regardless of mood. Furthermore, social situations cause positive emotions (McIntyre et al. 1991; Vittengl \& Holt, 2000). Therefore, behaviours within social situations may be relatively consistent, as positive emotions would be experienced while in the social situation.

\section{General Discussion}

The goal of this research was to examine the short-term changes in sociability due to mood manipulations while correcting possible confounds of prior research. All three studies found that people endorsed adjectives associated with sociability (or extraversion) more in the positive mood condition relative to the other conditions. Furthermore, the 
addition of a neutral condition provided a clearer picture of how moods influence feelings of sociability.

The preference for social over non-social situations showed mixed results for the three studies. Although, Study 3, with its careful selection of situations to remove the confound of pleasantness, showed people in positive moods reported greater desire for social over non-social situations. This aligns with Cunningham's (1988b) findings of people in elated moods reporting more engagement for social situations compared to people in neutral and depressed moods. The situational preferences found in Study 3 not only replicated the trends of Cunningham (1988b) and Study 1 while controlling for mood congruency but they have the additional advantage of allowing mood congruency (condition by pleasantness interaction) to be explored. Of note was that Study 3 did not provide support for mood congruency.

Future research would be warranted in exploring if positive moods result in the actual selection of a social over non-social situation (versus the theoretical decisions used by this research and prior research). Indirect support of real world situational preferences include Diener and Seligman's (2002) finding of very happy people spending more time interacting with others compared to unhappy people and Mehl, Gosling, and Pennebaker's (2006) findings that introverts spend more time alone compared to extraverts.

Unfortunately, when examining a variety of social behaviours no differences were found between the different mood conditions. This is a stark contrast to Cunningham's (1988a) findings of people in positive moods self-disclosing more than people in negative moods. To explore this discrepancy future studies would warrant including a measure of 
self-disclosure along with the social behaviours examined in Study 3. Moreover, additional measures of social behaviours including word count, posture, and tone of voice may warrant inclusion. Furthermore, social situations that are not as formal in nature may also be more effective in exploring behavioural differences due to moods. However, it is possible that positive moods may foster the preference for social situations without altering the behaviour within the situation. That is, positive moods may make people more likely to attend a party while behaviour at the party may not actually be altered (i.e., behaviour at a party would be the similar regardless of choosing to attend or being dragged by a friend).

The broaden-and-build theory proposes that positive emotions build social resources by creating more inclusive social categories that in turn foster social closeness. In a complementary process, positive moods were proposed to foster preferences for social situations. Study 3 shows that positive moods encourage preference for social interaction (both in feeling sociable and desire for social situations). This in turn can increase the opportunities for social interactions, to create inclusive social categories, and thus social closeness. Therefore, this research lends support to the broaden-and-build theory.

In exploring the core of extraversion, Lucas et al. (2000) reason that extraverts may select social situations due to the rewarding qualities of the situations and not their social characteristics. The situation findings of Study 3 question this reasoning. Study 3 shows that positive moods make people desire more social situations, regardless of pleasantness. As extraverts have higher set points of pleasant affect (i.e., are happier) compared to introverts, it follows that extraverts should also show a general preference 
for social situations over non-social situations, regardless of their pleasantness.

Furthermore, as extraverts have a general preference for pleasant situations (Lucas \& Diener, 2001), and social situations are generally more pleasant than non-social, Study 3 demonstrates that there is a possible additional mechanism which allows extraverts to select social over non-social situations. That is, extraverts' sensitivity to positive stimuli in all environments allows for their general happier set point that in turn fosters desire for social situations. This aligns with Lucas et al's stance that reward sensitivity is a fundamental feature of extraverts.

Strengths and Limitations

In exploring situational preferences due to mood manipulations, certain methodological improvements were made from prior research. First, emotional films were used to induce mood. This procedural adjustment had two distinct advantages. First, it removes demand effects of other mood induction procedures such as the Velten. Second, it allows for the premise of the study to be disguised and therefore eliminates another form of possible demand. Furthermore, Study 3 created a new measure of situations which was developed with careful selection of situations to remove the confound of pleasantness and thus. Moreover, in alignment with Cunningham (1988b), a control condition provided a clearer picture of how mood influences preference for social versus non-social situations and the implications of mood on feeling sociable.

Another strength of this research is with regards to social behaviours being examined through multiple measures (eye contact, subjective rating of sociable, talking time, etc). The discrepancy between Cunningham's (1988a) findings and the consistent lack of differences in social behaviours between mood conditions in Study 3 warrants 
further exploration. Including additional measures of social behaviours (such as word count, body language, and tone of voice) should be considered for future studies. A limitation of this research is with regards to the exploration of social behaviours in that only one social situation was used to examine social behaviours. The interviewerinterviewee interaction was short and used may have also been overly formal. Future studies may wish to select a less formal social interaction that lasts for a longer period of time.

Another limitation of this research is that the longer-term implications of positive moods impacting feeling sociable and preferring social situations was not established or explored. As positive moods were hypothesized to impact sociability on a short-term basis, the question still remains on how short-term (or long-term) the effects last for moods impacting sociability.

A limitation of this research is with regards to the sample which was limited to University students. Future research should explore if the findings reported here are replicated with more diverse, population representative samples. As this study examined the situational preferences and self-reported feelings of sociability based on moods, it is not believed that the sample differed on emotional responses compared to a more generalized population. Additionally, the situations selected were developed to be accessible to a University population and were rated on socialness and pleasantness by the population that was sampled. Therefore, this limitation is not perceived as serious.

\section{Conclusion}

Overall, this research supports the notion that positive moods cause increases in feeling social and preference for social over non-social situations. My three studies 
addressed the two major confounds of prior research in this area (namely demand effects and mood congruency). Interestingly, despite people reporting feeling more social, no differences in actual behaviours were found. Future research would be warranted in exploring social behaviours in that Study 3's lack of differences in behaviours is at odds with Cunningham's (1988a) findings. Moreover, future studies may wish to explore social behaviours employing additional measures (such as self-disclosure, body language, and tone of voice) in different more informal situations. As self-reports of feeling social did not correspond to differences in social behaviours, future research exploring hypothetical versus actual selection of situations would be merited. That is, people in positive moods reported more desire for social situations, relative to control and negative moods, but a direct test of selecting a social over non-social situation is justified.

Research has already established that socializing causes increases in pleasant affect (McIntyre et al. 1991; Vittengl \& Holt, 2000; Whelan, 2006, 2007). This research, along with Cunningham (1988b), established that positive moods cause an increase to desire to social situations. If this desire translates into real world selections of social over non-social situations then there is a reciprocal causal relation between positive moods and sociability. This dual directional link may be the keystone in trying to understand the personality differences of extraversion and introversion and their link to pleasant affect.

The real world implications for the causal link between positive emotions and sociability include determining the least demanding process for entering the cycle of positive moods and socializing reinforcing each other. That is, presumably once people can either join a social situation or be in a good mood, the reciprocal causal relationship between these aspects will then bestow additional positive moods (i.e., happiness). 


\section{References}

Atchison, D. (Writer/Director). (2006). Akeelah and the bee [Movie Picture]. United States: Spelling Bee Productions Inc.

Bower, G. H. (1991). Mood congruity of social judgments. In J. P. Forgas (Ed.), Emotion and Social Judgment (pp. 31-35). Oxford: Pergamon Press.

Buchwald, A. M., Strack, S., \& Coyne, J. C. (1981). Brief Reports: Demand Characteristics and the Velten mood induction procedure. Journal of Consulting and Clinical Psychology, 49, 478-479.

Carver, C. S., Sutton, S. K., \& Scheier, M. F. (2000). Action, emotion, and personality: Emerging conceptual integration. Personality and Social Psychology Bulletin, 26, $741-751$.

Cheek, J. M., \& Buss, A. H. (1981). Shyness and sociability. Journal of Personality and Social Psychology, 41, 330-339.

Clark, L. A., \& Watson, D. (1988). Mood and the mundane: Relations between daily life events and self-reported mood. Journal of Personality and Social Psychology, 54, 296-308.

Columbus, C. (Director) \& Levangie, G. (Writer). (1998). Stepmom [Movie Picture]. United States: Columbia Pictures.

Cunningham, M. R. (1988a). Does happiness mean friendliness? Induced mood and heterosexual self-disclosure. Personality and social psychology Bulletin, 14, 283297.

Cunningham, M. R. (1988b). What do you do when you're happy or blue? Mood expectancies and behavioral interest. Motivation and Emotion, 12, 309-331. 
Derryberry, D., \& Tucker, D. M. (1994). Motivating the focus of attention. In P. M. Niedental and S. Kitayama (Eds.), The Heart's Eye : Emotional Influences in Perception and Attention (pp. 170-196). USA: Academic Press.

Diener, E., Sandvik, E., Pavot, W., \& Fujita, F. (1992). Extraversion and subjective wellbeing in a U.S. national probability sample. Journal of Research in Personality, $26,205-215$.

Diener, E., \& Seligman, M. E. P. (2002). Very Happy People. Psychological Science, 13, 81-84.

Diener, E., Suh, E. M., Lucas, R. E., \& Smith, H. L. (1999). Subjective well-being: three decades of progress. Psychological Bulletin, 125, 276-302.

Eggleston, R. (Writer/Director). (1986). For the Birds [Movie Picture]. Pixar Animation Studios.

Eisler, R. M. (1976). Behavioral assessment of social skills. In M. Hersen \& A. S. Bellack (Eds.) Behavioral Assessment: A practical handbook (pp. 369-395). Great Britain: Pergamon Press.

Emmons, R. A., \& Diener, E. (1986). Influence of impulsivity and sociability on subjective well-being. Journal of Personality and Social Psychology, 50, 12111215.

Epstein, S. (1983). Aggregation and beyond: Some basic issues in the prediction of behavior. Journal of Personality, 51, 360-392.

Eysenck, H. J., \& Eysenck, M. W. (1985). Personality and individual differences. New York: Plenum Press. 
Fleeson, W. (2001). Towards a structure- and process-integrated view of personality: Traits as density distributions of states. Journal of Personality and Social Psychology, 80, 1011-1027.

Fleeson, W., Malanoz, A. B., \& Achille, N. M. (2002). An intraindividual process approach to the relationship between extraversion and positive affect: Is acting extraverted as "Good" as being extraverted? Journal of Personality and Social Psychology, 83, 1409-1422.

Fredrickson, B. L. (1998). What good are positive emotions? Review of General Psychology, 2, 300-319.

Fredrickson, B. L. (2001). The role of positive emotions in positive psychology: The broaden-and-build theory of positive emotions. American Psychologist, 56, 218226.

Greenwald, A. G. (1980). The totalitarian ego: Fabrication and revision of personal history. American Psychologist, 35, 603-618.

Harryson, M. (Director). (2006). Beowulf: performed by Benjamin Bagby [Movie Picture]. Sweden: Charles Morrow Productions.

Hills, P., \& Argyle, M. (2001). Happiness, introversion-extraversion and happy introverts. Personality and Individual Differences, 30, 595-608.

International Personality Item Pool (IPIP) A Scientific Collaboratory for the Development of Advanced Measures of Personality Traits and Other Individual Differences. Retrieved February 19, 2008 from http://ipip.ori.org Johnson, E. J., \& Tversky, A. (1983). Affect, generalization, and the perception of risk. Journal of Personality and Social Psychology, 45, 20-31. 
Kelley, C. (1982). Some effects of mood on attention and memory. Ph.D. Thesis, Stanford Psychology Department, Stanford University.

Larsen, R. J., \& Diener, E. (1992). Promises and problems with the circumplex model of emotion. In M. S. Clark (Ed.), Review of personality and social psychology, No 13. Thousand Oaks: CA. Sage Publications.

Larsen, R. J., \& Sinnett, L. M. (1991). Meta-analysis of experimental manipulations: Some factors affecting the Velten mood induction procedure. Personality and Social Psychology Bulletin, 17, 323-334.

Levenson, R. W. (1994). Human emotions: A functional view. In P. Ekman \& R. Davidson (Eds.), The nature of emotion: Fundamental questions (pp. 123-126). New York: Oxford University Press.

Lischetzke, T., \& Eid, M. (2006). Why extraverts are happier than introverts: The role of mood regulation. Journal of Personality, 74, 1127-1161.

Lucas, R. E., \& Diener, E. (2001). Understanding extraverts' enjoyment of social situations: The importance of pleasantness. Journal of Personality and Social Psychology, 81, 343-356.

Lucas, R. E., Diener, E., Grob, A., Suh, E. M., \& Shao, L. (2000). Cross-cultural evidence for the fundamental features of extraversion. Journal of Personality and Social Psychology, 79, 452-468.

Lucas, R. E., \& Fujita, F. (2000). Factors influencing the relation between extraversion and pleasant affect. Journal of Personality and Social Psychology, 79, 1039-1056. 
MacPhillamy, D. J., \& Lewinsohn, P. M. (1982). The Pleasant Events Schedule: Studies on reliability, validity, and scale intercorrelation. Journal of Consulting and Clinical Psychology, 50, 363-380.

Mayer, J. D., Gaschke, Y. N., Braverman, D. L., \& Evans, T. W. (1992). Moodcongruent judgement is a general effect. Journal of personality and social psychology, 63, 119-132.

Mehl, M. R., Gosling, S. D., \& Pennebaker, J. W. (2006). Personality in its natural habitat: Manifestatins and implicit fold theories of personality in daily life. Journal of Personality and Social Psychology, 90, 862-877.

McIntyre, C. W., Watson, D., Clark, L. A., \& Cross, S. A. (1991). The effect of induced social interaction on positive and negative affect. Bulletin of the Psychonomic Society, 29, 67-70.

Pavot, W., Diener, E., \& Fujita, F. (1990). Extraversion and happiness. Personality and Individual Differences, 11, 1299-1306.

Reeve, J. (2005). Understanding Motivation and Emotion (4th ed.). NJ: John Wiley \& Sons

Russell, J. A. (1980). A circumplex model of affect. Journal of Personality and Social Psychology, 39, 1161-1178.

Rusting, C. L. (1999). Interactive Effects of Personality and Mood on EmotionCongruent Memory and Judgment. Journal of Personality and Social Psychology, 77, 1073-1086.

Saucier, G. (1994). Mini-markers: A brief version of Goldberg's unipolar Big-Five markers. Journal of Personality Assessment, 63, 506-516. 
Schmidt, L. A., \& Fox, N. A. (1995). Individual differences in young adults' shyness and sociability: Personality and health correlates. Personality and Individual Differences, 19, 455-462.

Schneider, R. J., Ackerman, P. L., \& Kanfer, R. (1996). The "act wisely in human relations:" Exploring the dimensions of social competence. Personality and Individual Differences, 21, 469-481.

Shyamalan, M. N. (Writer/Director). 2002. Signs [Movie Picture]. United States: Touchstone Pictures.

Spitzberg, B. H., Brookshire, R. G., \& Brunner, C. (1990). The factorial domain of interpersonal skills. Social Behavior and Personality, 18, 137-150.

Taylor, S. E., \& Brown, J. D. (1988). Illusion and well-being: A social psychological perspective on mental health. Psychological Bulletin, 103, 193-210.

Tellegen, A. (1985). Structures of mood and personality and their relevance to assessing anxiety, with an emphasis on self-report. In A. H. Tuma \& J. D. Maser (Eds.), Anxiety and the anxiety disorders (pp. 681-706). Hillsdale, NJ: Earlbaum.

Velten, E. (1968). A laboratory task for induction of mood states. Behaviour Research and Therapy, 6, 473-82.

Vittengl, J. R., \& Holt, C. S. (2000). Getting acquainted: The relationship of selfdisclosure and social attraction to positive affect. Journal of Social and Personal Relationships, 17, 53-66.

Watson, D. (1988). Intraindividual and interindividual analyses of positive and negative affect: Their relation to health complaints, perceived stress, and daily activities. Journal of Personality and Social Psychology, 54, 1020-1030. 
Watson, D., \& Clark, L. A. (1997). Extraversion and its positive emotional core. In R. Hogan, J. Johnson, \& S. Briggs (Eds.), Handbook of personality psychology (pp. 767-793). San Diego, CA: Academic Press.

Watson, D., Clark, L. A., McIntyre, C. W., \& Hamaker, S. (1992). Affect, Personality, and social activity. Journal of Personality and Social Psychology, 63, 1011-1025.

Watson, D., Clark, L. A., \& Tellegen, A. (1988). Development and validation of brief measures of positive and negative affect: The PANAS scales. Journal of Personality and Social Psychology, 54, 1063-1070.

Waugh, C. E., \& Fredrickson, B. L. (2006). Nice to know you: Positive emotions, selfother overlap, and complex understanding in the formation of a new relationship. Journal of Positive Psychology, 1, 93-106.

Whelan, D. C. (2006). The emotional implications of acting extraverted: Does it depend on disposition? Unpublished bachelor's thesis, Carleton University.

Whelan, D. C. (2007). Extraverted Behaviour in the Context of Situational Demands: An Independent Exploration of Cognitive Fatigue and Emotional Implications. Unpublished manuscript, Carleton University.

Wright, W. E., \& Bower, G. H. (1992). Mood effects on subjective probability assessment. Organizational Behavior and Human Decision Processes, 52, 276291.

Zelenski, J. M., \& Larsen, R. J. (1999). Susceptibility to affect: A comparison of three personality taxonomies. Journal of Personality, 67, 761-791. 


\section{Footnotes}

${ }^{1}$ The terms extraverted or introverted will refer to individuals displaying more (or less) of the extraversion characteristics. Similarly, the term extravert or introvert will refer to people scoring high or low on the extraversion dimension without necessarily requiring an extreme score.

${ }^{2}$ As the situations were selected from Lucas and Diener (2001), I remained consistent with their rating scale. Specifically, Study 1 had participants report their desire for each situation whereas Study 2 asks participants to rate their predicted enjoyment of the situations.

${ }^{3}$ To explore mood congruence preference of situations, four separate $t$-tests were conducted (see Appendix F).

${ }^{4}$ Gender was explored in relation to all the measures of sociability (feeling extraverted, feeling sociable, situational preferences, and social behaviours). No main effects for gender were found. 
Appendix A - Trait Extraversion Assessment

\section{HOW ACCURATELY CAN YOU DESCRIBE YOURSELF?}

Please use this list of common human traits to describe yourself as accurately as possible. Describe yourself as you see yourself at the present time, not as you wish to be in the future. Describe yourself as you are generally or typically, as compared with other persons you know of the same sex and of roughly your same age.

Before each trait, please write a number indicating how accurately that trait describes you, using the following rating scale:

Not At

All

1

3

Somewhat

\begin{tabular}{|c|c|}
\hline Bashful & Energetic \\
\hline Bold & Envious \\
\hline Careless & Extraverted \\
\hline Cold & Fretful \\
\hline Complex & Harsh \\
\hline Cooperative & Imaginative \\
\hline _Creative & Inefficient \\
\hline Deep & Intellectual \\
\hline Disorganized & Jealous \\
\hline Efficient & Kind \\
\hline
\end{tabular}

\begin{tabular}{l}
$\ldots$ Moody \\
$\ldots$ Organized \\
$\ldots$ Philosophical \\
$\ldots$ Practical \\
$\ldots$ Quiet \\
$\ldots$ Relaxed \\
Rude \\
Shy \\
\hline Sloppy
\end{tabular}

Systematic Talkative Temperamental Touchy Uncreative Unenvious Unintellectual Unsympathetic Warm Withdrawn 
Appendix B - Affect and Feeling Extraverted Assessment

This scale consists of a number of words that describe different feelings and emotions. Read each item and then mark the appropriate answer in the space next to that word. Indicate to what extent you feel this way right now, at this moment. Use the following scale to record your answers:

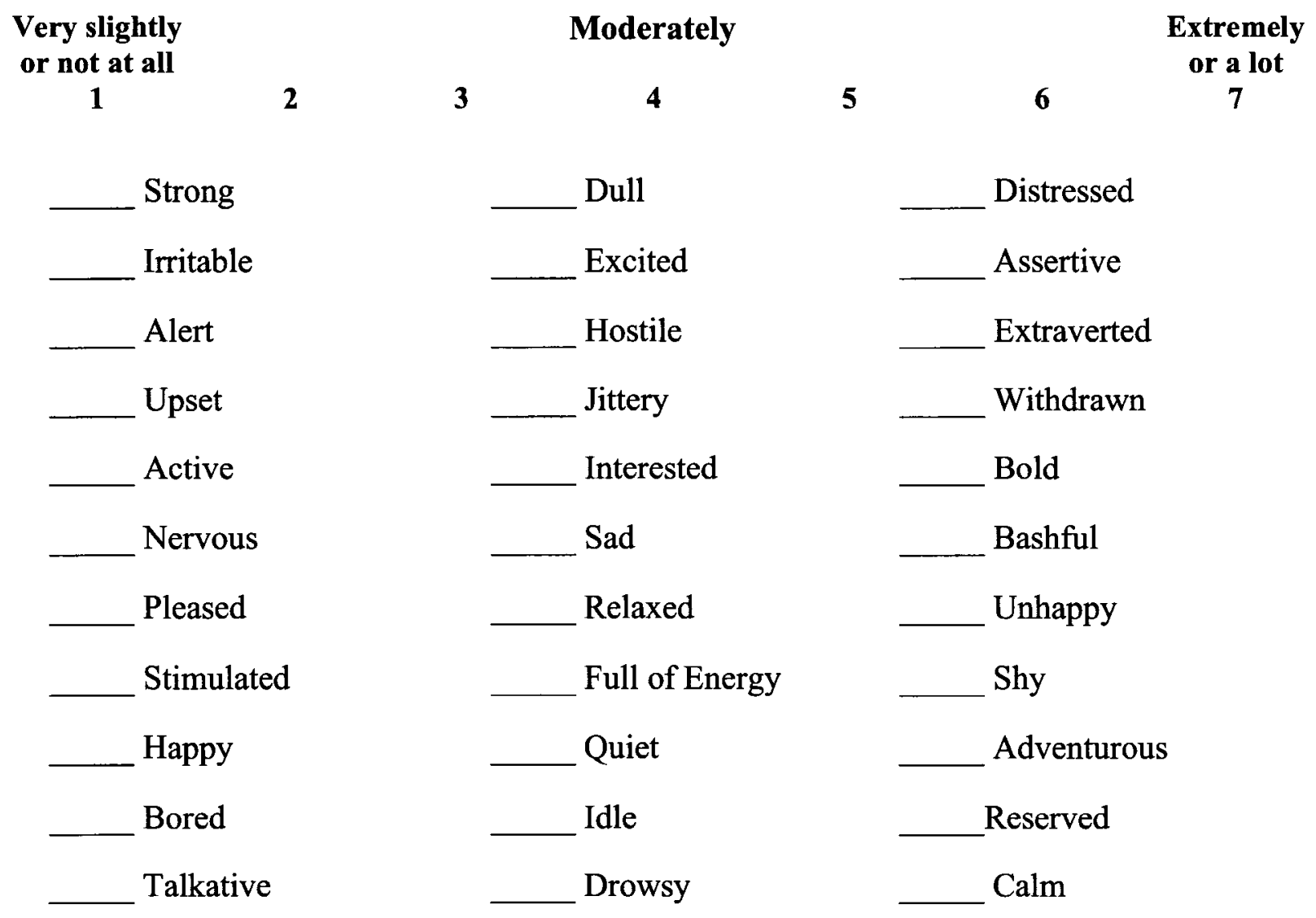




\section{Appendix C - Situations Questionnaire Study 1}

Please list how much you think you want to $D O$ the following right now, at this moment.

Very slightly or not at all

2

3

Moderately

4
Extremely

or a lot

7

1. Watching a movie alone.

2. Playing a team sport (such as soccer, baseball, volleyball, etc).

3. Studying for an upcoming quiz in a study group.

4. Talking with a group of friends about school/job.

5. Sitting alone beside a river listening to music.

6. Participating in a group discussion in class.

7. Making lunch in a quiet kitchen, alone.

8. Going to the movies with a group of friends from school.

9. Eating dinner with a group of friends.

10. Studying for your favourite subject alone in your room.

11. Going for a walk by yourself.

12. Being almost asleep, daydreaming, while listening to music.

13. Being in your room alone studying for a statistics test.

14. Having a few drinks with a bunch of friends.

15. In the library, reading for an upcoming class.

16. Working with class mates on a group project.

17. Talking with your manager during a staff meeting.

18. Cooking dinner with a small group of friends.

19. Playing solitaire.

20 . Doing laundry by yourself. 


$$
\text { Appendix D - Film Questionnaire }
$$

\section{Film and Personality}

Instructions: For each of the 6 items listed below, please rate how descriptive each statement is of you using the scale from $\mathbf{1}$ to 5 as shown below:

$\begin{array}{ccccc}\begin{array}{c}\text { Disagree } \\ \text { strongly }\end{array} & \begin{array}{c}\text { Disagree a } \\ \text { little }\end{array} & \begin{array}{c}\text { Neither agree } \\ \text { nor disagree }\end{array} & \text { Agree a little } & \begin{array}{c}\text { Agree } \\ \text { strongly }\end{array} \\ 1 & 2 & 3 & 4 & 5\end{array}$

1. ___ I enjoyed what I just watched.

3. ___ I found this movie or movie clip boring.

4. ___ I identified with a character(s) in this movie or movie clip.

5. ___ I'm sure I have seen this movie before today.

6. I I would recommend to a friend to watch this movie or movie clip. 
Appendix E - Situations Questionnaire Study 2

Please list how much you think you would ENJOY the following situations. right now, at this moment.

Very slightly or not at all

1
2
Moderately

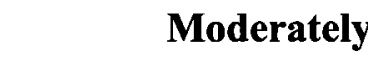

3
4
5
Extremely

or a lot

6

1. Talking to my best friend from home on the phone.

2. In English class, discussing a book.

3. Being almost asleep, daydreaming, while listening to music.

4. Walking back from class with my friend; complaining about how poorly I did on my BIOL 1001 test.

5. Driving across town by myself.

6. Talking with others while organizing my notes for a group project.

7. Studying accounting.

8. Eating lunch by myself while reading a book.

9. Sitting around the kitchen table with my friend, struggling over our music assignment.

10. Working as head bartender at a local bar.

11. Doing laundry by myself.

12. Being in a heated argument with my boyfriend/girlfriend.

13. Eating brunch and talking with friends.

14. Playing solitaire.

15. Jamming to my i-POD tunes, alone.

16. Talking on the phone to a lawyer.

17. Playing water polo and we were ahead 4 to 0 .

18. In my room alone, studying for my statistics test.

19. Playing guitar and singing, alone.

20. Typing a research proposal alone. 
Appendix F - Condition by Pleasantness Analysis (Study 2)

As the situation findings do not align with Study 1 , four additional t-tests were conducted exploring condition and pleasantness of situations. Specifically, the four categories of pleasantness (pleasant, moderately pleasant, moderately unpleasant, and unpleasant), as reported by Lucas and Diener (2001), were examined for condition differences. The only significant finding was for moderately unpleasant situations with those in the negative mood condition reporting they would enjoy the moderately unpleasant situations more compared to those in the positive mood condition. Comparison of Mood Conditions by Pleasantness of Situations (Study 2).

Condition

\begin{tabular}{|c|c|c|c|c|c|c|}
\hline \multirow[b]{2}{*}{ Situation Category } & \multicolumn{2}{|c|}{ Positive } & \multicolumn{2}{|c|}{ Negative } & \multirow[b]{2}{*}{$t$} & \multirow[b]{2}{*}{ Cohen's $d$} \\
\hline & $M$ & $S D$ & $M$ & $S D$ & & \\
\hline Pleasant & 4.59 & 0.93 & 4.47 & 0.99 & 0.43 & 0.12 \\
\hline Moderately Pleasant & 3.20 & 0.98 & 3.34 & 1.07 & -0.45 & 0.14 \\
\hline Moderately Unpleasant & 2.68 & 0.80 & 3.36 & 0.95 & $-2.62^{*}$ & 0.77 \\
\hline Unpleasant & 1.87 & 0.67 & 2.02 & 0.93 & -0.68 & 0.19 \\
\hline
\end{tabular}

* significant at family $\alpha<.05$ with Bonferoni 
Appendix G - Affect, Feeling Extraverted and Sociability Assessment

This scale consists of a number of words that describe different feelings and emotions. Read each item and then mark the appropriate answer in the space next to that word. Indicate to what extent you feel this way right now, at this moment. Use the following scale to record your answers:

\section{Very slightly} or not at all 1

Strong Irritable

Alert Upset

Active

Social

Nervous

Pleased

Stimulated

Impolite

Happy

Bored

Talkative
Moderately

4

5

6

Extremely or a lot

7
Dull

Excited

Hostile

Jittery

Friendly

Interested

Sad

Relaxed

Approachable

Full of Energy

Quiet

Idle

Drowsy
Distressed

Assertive

Extraverted

Withdrawn

Bold

Bashful

Antisocial

Unhappy

Shy

Adventurous

Gregarious

Reserved

Calm 
Appendix H -Situations for On-line Pre-Screening

1. Small talk with the cashier at the grocery store.

2. Play a team sport (such as soccer, baseball, volleyball, etc).

3. Wait in line, by yourself, at a fast food restaurant.

4. Do laundry by yourself.

5. Study for an upcoming quiz in a study group.

6. Talk with a group of friends about school/job.

7. Take photos of nature (flowers, plants, etc).

8. Participate in a group discussion in class.

9. Go to the movies with a group of friends from school.

10. Go out to eat dinner with a group of friends.

11. Be in your room alone studying for a statistics test.

12. Have a few drinks with a bunch of friends.

13. Bake cookies or a cake.

14. Walk home from school.

15. Work with classmates on a group project.

16. Talk with your manager during a staff meeting.

17. Sit in front of your computer watching youtube clips.

18. Attend a concert.

19. Go for a run.

20. Curl up with a good book.

21. Get a thank you card in the mail from a friend.

22. Go at a museum with a small group of friends

23. Look out at the stars on a clear summer evening.

24. Participate in a University clubs (martial arts, canoeing, intramurals, etc).

25. Head to the cottage for a quiet weekend alone.

26. Start a road trip with two of your closest friends.

27. Go to a BBQ.

28. Skate on the canal during Winterlude

29. Sit at a computer checking email.

30. Watch your favourite TV show by yourself. 
31. Watch Canada Day fireworks from Parliament Hill.

32. Have a group of friends over to play board games.

33. Go to the beach to suntan by yourself.

34. Listen to a good song as you drive to a friends place.

35. Take a long shower after a good workout.

36. Go to a small local fair with family.

37. Sleep in and relax after a busy week.

38. Cook dinner with a small group of friends.

39. Protest a cause that you believe in.

40. Take the dog for a long walk.

41. Go shopping with friends.

42. Attend a "networking" event for your department.

43. Sit by a fireplace and write in a journal.

44. Clean up after the family pet.

45. In a class learning how to play a musical instrument.

46. Take dance classes (swing, ballroom, tango, etc.).

47. Talk to the person next to you on a long flight.

48. Play loud music at home alone and dance.

49. Go camping with friends.

50. Wait in line with a friend at a government office (such as a passport office).

51. In the library, reading for an upcoming class.

52. Attend a family wedding.

53. Go shopping alone.

54. Read a book aloud to a group of young children.

55. Go for a jog on a beautiful summer evening.

56. Talk to the person sitting next to you on the bus.

57. Make lunch in a quiet kitchen, alone.

58. Be interviewed for a job.

59. Cook a simple but delicious meal.

60. Be almost asleep, daydreaming, while listening to music.

61. Ride in a car with a bunch of friends listening to music.

62. Receive constructive criticism from your manager. 
63. By yourself browsing in a bookstore.

64. Get groceries by yourself.

65. Talk to parents about school grades.

66. Wait for your friends to arrive at the pub when they're 20 minutes late.

67. Relax in a hot tub listening to the water.

68. Paint a room or piece of furniture by yourself.

69. Go out for coffee with an old friend.

70 . Go for a walk by yourself.

71. Sit with siblings looking out a window as a storm approaches.

72. Sit alone beside a river listening to music.

73. Attend a wine and cheese event.

74. Play solitaire.

75. Watch a movie alone at the movie theatre.

76. Mow the lawn on a spring day.

77. Wash the dishes.

78. Go to the market in the summer with a friend to get fresh fruits and vegetables.

79. Study for your favourite subject alone in your room.

80. Stuck in a traffic jam with 2 friends in the car.

81. In your room, late at night, trying out the latest video game.

82. Talk with 3 strangers while stuck in an elevator together. 
Appendix I - Situations Questionnaire Study 3

Please list how much you think you want to $D O$ the following right now, at this moment.

Very slightly or not at all

1
Moderately

2

3
4
Extremely or a lot 7

1. Play a team sport (such as soccer, baseball, volleyball, etc).

2. Do laundry by yourself.

3. Participate in a group discussion in class.

4. Work with classmates on a group project.

5. Look out at the stars on a clear summer evening.

6. Start a road trip with two of your closest friends.

7. Go to a BBQ.

8. Watch your favourite TV show by yourself.

9. Go to the beach to suntan by yourself.

10. Take a long shower after a good workout.

11. Sleep in and relax after a busy week.

12. Attend a "networking" event for your department.

13. In the library, reading for an upcoming class.

14. Make lunch in a quiet kitchen, alone.

15. Ride in a car with a bunch of friends listening to music.

16. Relax in a hot tub listening to the water.

17. Go out for coffee with an old friend.

18. Attend a wine and cheese event.

19. Play solitaire.

20. Talk with 3 strangers while stuck in an elevator together. 